\title{
Can Managerial Discretion Explain Observed Leverage Ratios?
}

\author{
Erwan Morellec \\ University of Lausanne and University of Rochester
}

\begin{abstract}
This article analyzes the impact of managerial discretion and corporate control mechanisms on leverage and firm value within a contingent claims model where the manager derives perquisites from investment. Optimal capital structure reflects both the tax advantage of debt less bankruptcy costs and the agency costs of managerial discretion. Actual capital structure reflects the trade-off made by the manager between his empire-building desires and the need to ensure sufficient efficiency to prevent control challenges. The model shows that manager-shareholder conflicts can explain the low debt levels observed in practice. It also examines the impact of these conflicts on the cross-sectional variation in capital structures.
\end{abstract}

Since Modigliani and Miller (1958), economists have devoted much effort to studying the financing policies of firms. The capital structure of a firm is now regarded as being determined by a broad range of factors including taxes, bankruptcy costs, and conflicts of interests among claim holders. Yet despite the development of this literature, its applications have been limited by the fact that it only provides qualitative guidance.

Contingent claims models provide a consistent framework for multiperiod valuation and hence it has been argued that they could offer a useful framework to analyze firms' financing policies. ${ }^{1}$ But when applied to capital structure decisions, these models suffer from two major limitations. First, for reasonable input parameter values, they generate leverage ratios that exceed those observed in practice. Second, these models cannot reproduce the cross-sectional variation in capital structures. One potential explanation for these limitations is that these models have overlooked some determinants of debt policy - in particular the impact of agency conflicts on firms' financing decisions. ${ }^{2}$

\footnotetext{
I thank my dissertation adviser Bernard Dumas for invaluable guidance. The editor (Mike Fishman) and two anonymous referees provided detailed comments that substantially improved the article. Comments by Rui Albuquerque, Mike Barclay, Pascal François, Dirk Hackbarth, Cliff Smith, and Mike Yang are also gratefully acknowledged. The usual caveat applies. Address correspondence to Erwan Morellec, Simon School of Business, University of Rochester, Rochester NY 14627, or e-mail: morellec @simon. rochester.edu.

${ }^{1}$ See Leland (1994), Leland and Toft (1996), Fan and Sundaresan (2000), Goldstein, Ju, and Leland (2001), Duffie and Lando (2001), Lambrecht (2001), or François and Morellec (2004).

${ }^{2}$ Contingent claims models generally assume that the firm's investment policy is fixed and determine optimal leverage by balancing the tax advantage of debt and bankruptcy costs. See however Mello and Parsons (1992), Morellec (2001), Hennessy (2003), and Ju, Parrino, Poteshman, and Weisbach (2003).
} 
The notion that agency conflicts affect a firm's capital structure is now widely accepted. The costs associated with stockholder-bondholder conflicts (underinvestment and asset substitution) typically increase with the amount of debt in the firm's capital structure and with the number of growth options available to the firm. It thus has been suggested that these conflicts could explain both the low amounts of debt issued by firms and the fact that high-growth-option firms tend to use lower quantities of debt [see Smith and Watts (1992) or Rajan and Zingales (1995)].

A recent controversy, however, has emerged as to whether stockholder-bondholder conflicts could underlie the observed debt levels and the cross-sectional evidence on leverage. First, in his analysis of the asset substitution problem, Leland (1998, p. 1229) finds that "optimal leverage when an agency problem exists exceeds that of a firm that cannot increase risk." Second, Parrino and Weisbach (1999) conclude from their numerical analysis that "distortions from stockholder-bondholder conflict [...] are too small to explain the observed cross-sectional variation in capital structure." 3

Another commonly discussed determinant of capital structure arises from manager-stockholder conflicts. Managers and shareholders have different objectives. In particular, managers tend to value investment more than shareholders do. As Jensen (1986) argues, debt financing can increase firm value by reducing the costs associated with this conflict. Two possible conclusions emerge from this analysis. First, it may be optimal for shareholders to increase leverage when managers follow personal objectives. Second, if managers have discretion over financing policies, firms will issue less debt than optimal. ${ }^{4}$

While manager-stockholder conflicts have been widely discussed in qualitative terms, the literature has largely been silent on the magnitude of their effects. As illustrated by the analyses of Leland (1998) and Parrino and Weisbach (1999), the importance of these ideas ultimately depends on the magnitude of the underlying conflicts and their ability to explain the observed behavior of firms.

This article develops a contingent claims model of the firm where debt financing affects not only taxes and costs of financial distress but also the firm's investment policy. In this environment, I analyze the impact of the opportunistic behavior of the manager on asset prices, leverage decisions, and firm value. ${ }^{5}$ Several important results follow from this analysis. First,

\footnotetext{
${ }^{3}$ Recent work by Johnson (2002) shows that underinvestment costs may explain other dimensions of firms' financing policies, such as the choice of debt maturity.

${ }^{4}$ This is consistent with the finding in Graham (2000) that firms use debt too conservatively.

${ }^{5}$ Important related work by Parrino, Poteshman, and Weisbach (2001) analyzes in a dynamic setting manager-stockholder conflicts. In their framework, these conflicts of interest arise because of managerial risk aversion and result in deviations from value maximization in investment policy.
} 
the model explains how the various determinants of leverage interact to determine capital structure decisions and firm value. Second, it shows that manager-shareholder conflicts can explain the low debt level observed in practice. Third, it relates capital structure decisions to the firm's investment opportunity set and shows that agency conflicts can explain the observed cross-sectional variation in capital structures.

Consider a firm with both assets in place and investment projects. The incumbent manager has specific human capital in administering the firm's assets and thus is partially entrenched. But because of the private benefits he derives from investment, the manager tends to overinvest, thereby giving rise to agency costs of free cash flow.

When capital structure is chosen to maximize equity value, the optimal debt-equity mix is obtained by balancing the benefits and the costs of debt. Debt increases firm value because it provides a tax shield and reduces the free cash flow. However, debt is costly because it induces underinvestment in the firm's growth options and increases expected bankruptcy costs. While standard free cash flow models presume that it is always optimal to constrain management, I show that these other factors affect shareholders' willingness to do so. The model determines both the impact of agency costs on optimal leverage and the magnitude of agency costs at optimal leverage.

When capital structure decisions are made by the manager, the actual choice of debt differs from the optimal one. Specifically, empire-building desires induce entrenched managers to issue less debt than optimal. However, when the policy choices of the manager erode firm value, the manager can face the threat of a control challenge. In such situations, the manager has an incentive to increase leverage in order to precommit to an investment policy that will avoid excessive deviations from value maximization. The analysis in the article demonstrates that the number of growth options in the firm's investment opportunity set plays a crucial role in determining the selected financing policy. In particular, as the number of growth options rises, the cost of overinvestment decreases and thus the debt level that prevents control challenges goes down.

The remainder of article is organized as follows. Section 1 describes the model. Leverage decisions are analyzed in Section 2. Section 3 discusses implications. Section 4 presents extensions. Section 5 concludes.

\section{Managerial Discretion and Asset Prices}

\subsection{Assumptions}

Throughout the article, capital markets are perfect with no transaction costs. The default-free term structure is flat with an instantaneous riskfree rate $r$, at which investors may lend and borrow freely. I consider a 
firm composed of a set of assets in place that generate revenues which are positively related to a state variable $x_{t}$. In combination with the human capital of the manager, these assets yield an instantaneous operating profit given by

$$
f_{(\delta)}\left(x_{t}\right)=\delta x_{t}-c,
$$

where $\delta-1 \geq 0$ represents the value added by the incumbent manager to assets in place, $c \geq 0$ is a constant flow cost per period that includes the manager's fixed wage $w$, and $\left(x_{t}\right)_{t \geq 0}$ is ruled by the diffusion process,

$$
d x_{t}=\mu x_{t} d t+\sigma x_{t} d Z_{t}, \quad x_{0}>0 .
$$

In Equation (2), $\left(Z_{t}\right)_{t \geq 0}$ is a standard Brownian motion defined on a probability space $(\Omega, \mathcal{F}, \mathcal{Q})$ and $\mu$ and $\sigma$ are constant parameters with $\mu<r$.

At each time $t$, cash flows from assets in place may be reinvested in new projects. I denote the number of positive net present value (NPV) projects available to the firm per unit of time by $I^{*}$. (Because $I^{*}$ reflects the number of positive-NPV projects available to the firm in the future, $I^{*}$ gives a measure of the number growth options in the firm's investment opportunity set.) Following Stulz (1990), I presume that the marginal product of investment is decreasing and given by a step function. Specifically, the payoff from investment is $H>1$ per unit for the first $I^{*}$ units. Investment levels beyond $I^{*}$ but less than $J>I^{*}$ yield $L$ per unit with $L<1$. Investment levels beyond $J$ yield zero per unit. This specification captures in a simple fashion the idea that overinvestment is more severe for firms that generate greater cash flows, either structurally (high $x_{0}$ ) [see Harford (1999)] or occasionally (high $\sigma$ ) [see Blanchard, Lopes-de-Silanes, and Shleifer (1994)]. ${ }^{6}$

Although the firm may operate its assets forever, it also can choose to abandon operations. I presume thereafter that by abandoning operations, the firm loses its growth options. Moreover, I presume that the abandonment decision is irreversible. As a result, this decision may be viewed as the decision to liquidate the firm. The abandonment value of the firm is denoted by $A\left(x_{t}\right)$.

Manager-stockholder conflicts are introduced by considering that, in addition to his fixed wage, the manager derives utility from both retaining control and investing in new projects. For simplicity I presume that the benefits the manager receives from each activity are additively separable. In particular, the manager derives utility $\phi$ per unit of investment and $\varphi v_{(\delta)}^{\phi}(\cdot)$ from retaining control, where $\varphi<1$ and $\phi \in[(1-L) \varphi, \varphi]$ are

\footnotetext{
${ }^{6}$ This specification has been chosen for simplicity of exposition. As the number of relevant intervals for the marginal product of investment increases, the underlying production function converges to a standard continuous technology with decreasing returns to scale.
} 
positive constants, and $v_{(\delta)}^{\phi}(\cdot)$ denotes firm value. ${ }^{7}$ (Section 3 provides an analysis of the determinants of the optimal $\varphi$.) These assumptions imply that the utility of the manager increases with the projects' NPV. Thus the manager will invest first in the positive-NPV projects. ${ }^{8}$ These assumptions also imply that it is optimal for the manager to invest up to $J$ units of capital. Therefore the manager has (limited) incentives to invest in negative-NPV projects when positive-NPV projects are exhausted. In particular, free cash flow beyond $J$ is paid out to shareholders.

Agency costs of managerial discretion typically depend on the allocation of control rights within the firm. Throughout the article the manager has decision rights over financing and investment policies. (I discuss below the allocation of control rights with respect to the decision to default.) I also presume that cash flows and investment decisions, although observable, are not verifiable and thus are not contractible. However, the policy choices of the manager are constrained by the external market for corporate control. In particular, policy choices that imply larger deviations from value maximization increase the likelihood of a control challenge. I also consider that (i) control challenges are costly and (ii) operation of the firm's assets without the incumbent yields operating profits given by

$$
f_{(1)}\left(x_{t}\right)=x_{t}-c .
$$

According to Equations (1) and (3), the incumbent manager has specific skills in administering the firm's assets. Because of these specific skills, the manager is partially entrenched and thus has some discretion over policy choices. I presume below that this specific human capital is associated with the initial manager only. Thus successful control challenges put an end to entrenchment and the replacement manager acts on behalf of shareholders. That is, overinvestment costs are zero for alternative managers. ${ }^{9}$

\subsection{Value of the unlevered firm}

Before analyzing the role of debt financing in constraining management, it will be useful to identify the sources of value within the firm. Firm value is given by the combination of the values of its assets in place and investment opportunities. In particular, firm value can be written as the sum of the value of a perpetual entitlement to the current flow of income, the value of

\footnotetext{
${ }^{7}$ These assumptions imply that the manager's compensation is linear in firm value. The analysis of the optimal contract for the manager is beyond the scope of this article. Holmstrom and Milgrom (1987) and Shätler and Sung (1993) provide an analysis of optimal contracting in continuous-time principal-agent models. While all these articles establish the optimality of linear contracts, the set of assumptions they rely on differ from the ones underlying the present model and hence their conclusions may not apply to the present setting.

${ }^{8} \mathrm{I}$ assume below that the manager can always raise funds to finance positive-NPV projects. Thus there is no need to transfer funds from one period to another to exhaust positive-NPV projects.

${ }^{9}$ The basic proposition underlying this assumption is that there are more substitutes for the alternative manager. As a result, this manager has less discretion and overinvestment is less severe.
} 
the firm's investment opportunities, and the value of the option to abandon operations. ${ }^{10}$ I denote the first passage time of $\left(x_{t}\right)_{t \geq 0}$ at $y$ by $T(y)$ and the expectation operator associated with the measure $\mathcal{Q}$ conditional on $x$ starting at the level $x_{0}$ by $E_{\mathcal{Q}}^{x_{0}}$. If agents are risk neutral, firm value can be written as

$$
\begin{aligned}
v_{(\delta)}^{\phi}\left(x_{0}\right)= & E_{\mathcal{Q}}^{x_{0}}\left[\int_{0}^{T\left(x_{(\delta)}^{u}\right)} e^{-r t}(1-\tau)\left[f_{(\delta)}\left(x_{t}\right)+(H-1) I^{*}\right] d t+e^{-r T\left(x_{(\delta)}^{u}\right)} A\left(x_{(\delta)}^{u}\right)\right] \\
& +E_{\mathcal{Q}}^{x_{0}}\left[\int_{0}^{T\left(x_{(\delta)}^{u}\right)} e^{-r t}(1-\tau)(L-1)\left[\min \left(f_{(\delta)}\left(x_{t}\right), J\right)-I^{*}\right] \mathbf{1}_{f\left(x_{t}\right) \geq I^{*}} d t\right],
\end{aligned}
$$

where $\tau$ denotes the corporate tax rate, $\mathbf{1}_{\omega}$ is the indicator function of the event $\omega$, and $x_{(\delta)}^{u}$ is the selected abandonment threshold. The first term on the right-hand side of Equation (4) is the sum of the expected present value of the cash flows from assets in place and positive-NPV projects and the liquidation value of the firm. The second term represents the cost of overinvestment. Equation (4) shows that, because information is observable and the manager derives utility from firm value, shareholders inject cash in the firm when the firm does not have enough cash on hand to finance efficient investment decisions. ${ }^{11}$ By contrast, overinvestment is limited by the availability of internal sources of funds.

Solving Equation (4) yields for $f_{(\delta)}\left(x_{0}\right) \leq I^{*}$ (see the appendix),

$$
\begin{aligned}
v_{(\delta)}^{\phi}\left(x_{0}\right)= & (1-\tau)\left(\frac{\delta x_{0}}{r-\mu}-\frac{c}{r}\right)-(1-\tau)\left(\frac{\delta x_{(\delta)}^{u}}{r-\mu}-\frac{c}{r}\right)\left(\frac{x_{0}}{x_{(\delta)}^{u}}\right)^{\vartheta} \\
& +A\left(x_{(\delta)}^{u}\right)\left(\frac{x_{0}}{x_{(\delta)}^{u}}\right)^{\vartheta}+\frac{(1-\tau)(H-1) I^{*}}{r}\left[1-\left(\frac{x_{0}}{x_{(\delta)}^{u}}\right)^{\vartheta}\right] \\
& +\frac{(1-\tau)(L-1) \sigma\left[\left(c+I^{*}\right)^{1-\xi}-(c+J)^{1-\xi}\right]}{\lambda(\lambda-\sigma-b)(\lambda-b)\left(\delta x_{0}\right)^{-\xi}}\left[1-\left(\frac{x_{0}}{x_{(\delta)}^{u}}\right)^{\vartheta-\xi}\right],
\end{aligned}
$$

where $b=\left(\mu-\sigma^{2} / 2\right) / \sigma, \lambda=\sqrt{2 r+b^{2}}, \vartheta=-(b+\lambda) / \sigma$, and $\xi=(\lambda-b) / \sigma$.

In a model where the manager acts in the best interests of shareholders, firm value equals the expected present value of the cash flows from assets

\footnotetext{
${ }^{10}$ I presume that there exists a value of $x$ in $\mathbb{R}_{++}$for which it is optimal to abandon operations. When $c<I^{*}(H-1)$, the optimality of abandonment ultimately depends on the functional form of the value function $A(x)$. This issue is addressed below in the analysis of leverage decisions.

${ }^{11}$ Section 4 analyzes the impact of financing constraints on underinvestment costs.
} 
in place [the first three terms on the right-hand side of Equation (5)] plus the NPV of the growth options [the fourth term in Equation (5)]. In the present model the manager derives perquisites from investment and thus has an incentive to overinvest. The agency cost of managerial discretion depends on the level of resources available for investment and satisfies

$$
\begin{aligned}
A C_{(\delta)}^{\phi}\left(x_{0}\right)= & \frac{(1-\tau)(L-1) \sigma\left[\left(c+I^{*}\right)^{1-\xi}-(c+J)^{1-\xi}\right]}{\lambda(\lambda-\sigma-b)(\lambda-b)\left(\delta x_{0}\right)^{-\xi}}\left[1-\left(\frac{x_{0}}{x_{(\delta)}^{u}}\right)^{\vartheta-\xi}\right] \\
& +\left[\frac{(1-\tau)\left[(H-1) I^{*}+c\right]}{r}+A\left(x_{(\delta)}^{u}\right)-\frac{(1-\tau) \delta x_{(\delta)}^{u}}{r-\mu}\right]\left(\frac{x_{0}}{x_{(\delta)}^{u}}\right)^{\vartheta} \\
& -\left[\frac{(1-\tau)\left[(H-1) I^{*}+c\right]}{r}+A\left(x_{(\delta)}^{*}\right)-\frac{(1-\tau) \delta x_{(\delta)}^{*}}{r-\mu}\right]\left(\frac{x_{0}}{x_{(\delta)}^{*}}\right)^{\vartheta},
\end{aligned}
$$

where $x_{(\delta)}^{*}$ is the firm's abandonment threshold when the manager acts in the best interests of shareholders. In this equation, the first term on the right-hand side represents the decrease in the value of the firm's investment opportunities due to overinvestment. The second and third terms account for the impact of the change in the abandonment policy of the firm due to the empire-building desires of the manager. In particular, overinvestment by the manager leads to late exit when the manager has decision rights over the abandonment policy of the firm and to early exit when shareholders have these decision rights.

Equations (5) and (6) show that two sources of inefficiency arise when the firm is unlevered. First, the firm does not benefit from the debt tax shield. Second, overinvestment by the manager lowers firm value by changing the firm's abandonment policy and by reducing the value of its investment opportunities. As Jensen (1986) argues, debt can control the free cash flow problem by limiting the resources under the manager's control. The next section examines the impact of corporate debt on investment policy and firm value.

\subsection{Debt financing}

In this section I analyze the impact of debt financing on firm value. I consider debt contracts which are characterized by (i) a perpetual flow of coupon payments s and (ii) a commitment that if the firm defaults on its debt obligations, it is immediately liquidated. ${ }^{12}$

\footnotetext{
${ }^{12}$ I assume that renegotiation of the debt contract upon default is prohibitively costly. Fan and Sundaresan (2000), David (2001), and François and Morellec (2002) analyze the effects of debt renegotiation on the valuation of corporate securities and leverage choices.
} 
I denote the values of equity and corporate debt when the firm has issued debt with contractual coupon payment $s$ by $e_{(\delta)}^{\phi}(x, s)$ and $d_{(\delta)}^{\phi}(x, s)$. Shareholders have limited liability and thus the option to default on their obligations. The optimal policy for shareholders is to default when equity value is zero. This stock-based definition of default has important implications for the valuation of corporate securities. First, it implies that it is optimal for shareholders to inject capital in the firm as long as the firm has positive economic net worth. Second, it implies that the firm is insolvent on a flow basis at the default date. Therefore the manager cannot operate the firm's assets beyond the default date that maximizes equity value and shareholders have control rights over the decision to default. Third, it implies that if absolute priority is enforced, shareholders get nothing upon default. As a result, the values of equity and corporate debt, respectively, satisfy

$$
\begin{aligned}
& e_{(\delta)}^{\phi}\left(x_{0}, s\right) \\
& \quad=E_{\mathcal{Q}}^{x_{0}}\left[\int_{0}^{T\left(x_{(\delta)}^{l}\right)} e^{-r t}(1-\tau)\left(f_{(\delta)}\left(x_{t}\right)+(H-1) I^{*}-s\right) d t\right] \\
& +E_{\mathcal{Q}}^{x_{0}}\left[\int_{0}^{T\left(x_{(\delta)}^{l}\right)} e^{-r t}(1-\tau)(L-1)\left[\min \left(f_{(\delta)}\left(x_{t}\right)-s, J\right)-I^{*}\right] \mathbf{1}_{f_{(\delta)}\left(x_{t}\right)>s+I^{*}} d t\right],
\end{aligned}
$$

and

$$
d_{(\delta)}^{\phi}\left(x_{0}, s\right)=E_{\mathcal{Q}}^{x_{0}}\left[\int_{0}^{T\left(x_{(\delta)}^{l}\right)} e^{-r t} s d t+e^{-r T\left(x_{(\delta)}^{l}\right)} A\left(x_{(\delta)}^{l}\right)\right],
$$

where $x_{(\delta)}^{l}$ denotes the default threshold selected by shareholders.

Solving Equations (7) and (8) yields for $f_{(\delta)}(x) \leq I^{*}+s$,

$$
\begin{aligned}
& e_{(\delta)}^{\phi}\left(x_{0}, s\right) \\
& =(1-\tau)\left(\frac{\delta x_{0}}{r-\mu}-\frac{c+s}{r}\right)-(1-\tau)\left(\frac{\delta x_{(\delta)}^{l}}{r-\mu}-\frac{c+s}{r}\right)\left(\frac{x_{0}}{x_{(\delta)}^{l}}\right)^{\vartheta} \\
& +\frac{(1-\tau)(H-1) I^{*}}{r}\left[1-\left(\frac{x_{0}}{x_{(\delta)}^{l}}\right)^{\vartheta}\right] \\
& +\frac{(1-\tau)(L-1) \sigma\left[\left(c+s+I^{*}\right)^{1-\xi}-(c+s+J)^{1-\xi}\right]}{\lambda(\lambda-\sigma-b)(\lambda-b)\left(\delta x_{0}\right)^{-\xi}}\left[1-\left(\frac{x_{0}}{x_{(\delta)}^{l}}\right)^{\vartheta-\xi}\right],
\end{aligned}
$$


and

$$
d_{(\delta)}^{\phi}(x, s)=\frac{s}{r}+\left[A\left(x_{(\delta)}^{l}\right)-\frac{s}{r}\right]\left(\frac{x_{0}}{x_{(\delta)}^{l}}\right)^{\vartheta} .
$$

In these equations the first term on the right-hand side represents the value of a perpetual entitlement to the current flow of income. The second term is the product of the change in asset value occurring upon default and the present value of one dollar contingent on default. The third term on the right-hand side of Equation (9) accounts for the value of the firm's positive-NPV projects. The fourth term represents the cost of overinvestment. This term reflects the fact that the manager will not invest more than $J$ units of capital at any point in time.

The stock-based definition of default used in this article implies that the firm is insolvent on a flow basis at the default date. Thus, under the assumption that the manager does not have "deep pockets," default is triggered by shareholders' decision to cease injecting funds in the firm and shareholders have control rights over the default decision. The first-best default policy for shareholders consists of selecting the default threshold that maximizes equity value. Therefore the default threshold satisfies the smooth-pasting condition [see Dumas (1991)]:

$$
\left.\frac{\partial e_{(\delta)}^{\phi}(x, s)}{\partial x}\right|_{x=x_{(\delta)}^{l}}=0 .
$$

Solving Equation (11) yields ${ }^{13}$

$$
\begin{aligned}
& \frac{\vartheta}{\vartheta-1} \frac{c+s-(H-1) I^{*}}{r} \\
& \quad=\frac{\delta x_{(\delta)}^{l}}{r-\mu}+\frac{\vartheta-\xi}{\vartheta-1} \frac{(L-1) \sigma\left[\left(c+s+I^{*}\right)^{1-\xi}-(c+s+J)^{1-\xi}\right]}{\lambda(\lambda-\sigma-b)(\lambda-b)\left(\delta x_{(\delta)}^{l}\right)^{-\xi}} .
\end{aligned}
$$

Equation (12) indicates that shareholders take into account the impact of leverage on the value of the firm's investment opportunities in their decision to default. This impact is represented in Figure 1, which plots the default threshold selected by shareholders as a function of the number of growth options available to the firm. Figure 1 shows that the default threshold selected by shareholders decreases with the number of growth

\footnotetext{
${ }^{13}$ Equation (12) also corresponds to the first-order condition from maximizing Equation (9) with respect to $x_{(\delta)}^{l}$.
} 


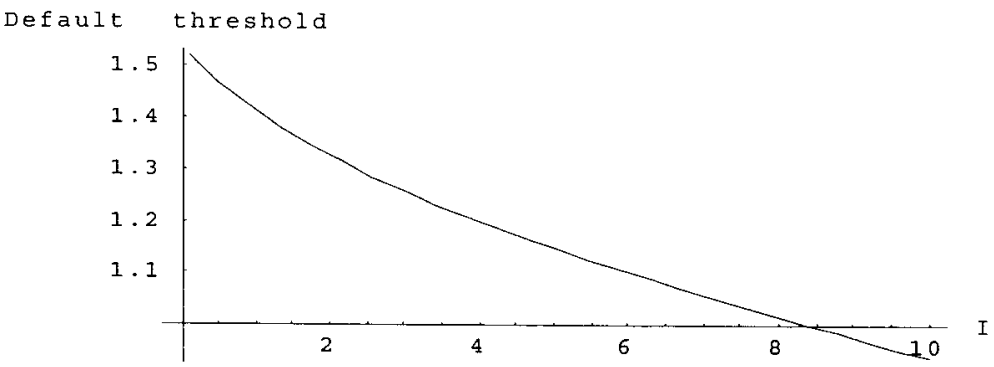

Figure 1

Growth options and default threshold

Plots the default threshold selected by shareholders at optimal leverage as a function of the number of growth options in the firm's investment opportunity set for $I^{*} \in[1,15]$. Input parameter values are set as follows: the risk-free interest rate, $r=6 \%$; the differential productivity of the incumbent versus the next best alternative, $\delta-1=5 \%$; the state variable drift, $\mu=0.01$; the volatility of returns on cash flows from assets in place, $\sigma=25 \%$; constant operation costs, $c=1$; the tax advantage of debt, $\tau=15 \%$; and liquidation costs, $\alpha=25 \%$. The return on investment is $H=1.1$ per unit for the first $I^{*}$ units. Investment levels beyond $I^{*}$ but less than $J$ yield $L=0.9$ per unit.

options available to the firm. As the number of positive-NPV projects increases, the potential costs of overinvestment decrease while the potential costs of underinvestment increase. It is therefore optimal for shareholders to postpone the default decision. In the standard contingent claims model of the firm, increasing leverage increases the default threshold because the opportunity cost of remaining active is higher. In the present model, this effect is mitigated by the positive impact of leverage on the value of the firm's investment opportunities.

\section{Leverage Decisions}

\subsection{Optimal leverage}

Before turning to the analysis of leverage decisions, it is important to make a clear distinction between the value of equity ex ante-at the time of debt issuance - and ex post - after debt has been issued. The value of equity ex post is given by the present value of the cash flows accruing to shareholders after the debt has been sold [see Equations (7) and (9)]. The value of equity ex ante is given by the sum of the value of equity ex post and the market value of debt at the time it is issued. As a result, although the default threshold typically is selected ex post to maximize equity value [Equation (11)], optimal leverage is determined ex ante to maximize firm value, $v_{(\delta)}^{\phi}\left(x_{0}, s\right)$.

The above arguments demonstrate that optimal capital structure is defined by the debt level $s_{(\delta)}^{*}$ that maximizes firm value. Within the present 
model, firm value is given by (see the appendix for the solution to this equation)

$$
\begin{aligned}
& v_{(\delta)}^{\phi}\left(x_{0}, s\right) \\
& =E_{\mathcal{Q}}^{x_{0}}\left[\int_{0}^{T\left(x_{(\delta)}^{l}\right)} e^{-r t}(1-\tau)\left(f_{(\delta)}\left(x_{t}\right)+(H-1) I^{*}+\tau s\right) d t+e^{-r T\left(x_{(\delta)}^{l}\right)} A\left(x_{(\delta)}^{l}\right)\right] \\
& +E_{\mathcal{Q}}^{x_{0}}\left[\int_{0}^{T\left(x_{(\delta)}^{l}\right)} e^{-r t}(1-\tau)(L-1)\left[\min \left(f_{(\delta)}\left(x_{t}\right)-s, J\right)-I^{*}\right] \mathbf{1}_{f_{(\delta)}\left(x_{t}\right)>s+I^{*}} d t\right] .
\end{aligned}
$$

Equation (13) reveals that debt financing affects firm value in four ways. First, debt provides a tax shield. Second, debt affects bankruptcy costs by changing the default policy of the firm. Third, debt induces underinvestment when cash flows from assets in place are low (i.e., the firm loses its positive-NPV projects upon default). ${ }^{14}$ Fourth, debt improves the firm's investment policy when cash flows from assets in place are high by limiting the resources the manager can invest in new projects. ${ }^{15}$

Equation (13) indicates that two main effects determine the impact of agency costs of managerial discretion on optimal leverage. First, shareholders' willingness to improve the investment policy of the firm using debt depends on the magnitude of the overinvestment cost. As a result, it depends not only on the profitability of assets in place but also on taxes, costs of financial distress, and the number of growth options available to the firm. Second, because debt financing induces underinvestment and bankruptcy costs, the debt policy that maximizes firm value may not eliminate the free cash flow problem.

While shareholders would like the manager to select the debt level that maximizes firm value, the manager is unlikely to implement this financing policy. In particular, the preferences of the manager and the costs imposed by control challenges will typically induce deviations of selected financial policies from value-maximizing financing policies. I now turn to the analysis of managerial leverage decisions.

\footnotetext{
${ }^{14}$ The corporate finance literature has modeled at least three types of leverage-related circumstances that lead to a failure to undertake positive-NPV projects: stockholder-bondholder conflicts [Myers (1977)], default [Stulz (1990)], and financing constraints [Fazzari, Hubbard, and Petersen (1988)]. Although these mechanisms are not mutually exclusive, I focus in the basic model of this article on the second source of underinvestment costs (however, see Section 4 below).

${ }^{15}$ Because the overinvestment cost depends on the initial value of the firm cash flows, the optimal leverage ratio also depends on this value. This feature of the model is common to all models in which the functionals defining asset prices depend on the starting state of the system [see Fan and Sundaresan (2000)]. However, because the firm cash flow is given by a (piecewise) continuous, borel-bounded function, the value functions are piecewise $C^{2}$ [see Karatzas and Shreve (1991, Theorem 4.9, p. 271)] This property of the value functions implies that they are $C^{1}$ and $C^{0}$ at the overinvestment threshold $\left(x=c+s+I^{*}\right)$, which in turn ensures that the mapping $x \mapsto s_{(\delta)}^{*}$ is continuous on the entire state space.
} 


\subsection{Unconstrained choice of leverage}

Deviations from optimal financing policies implied by managerial discretion depend on the impact of the manager's preferences on leverage decisions. Within the present model, the manager derives utility from both undertaking new projects and retaining control. The first component of this utility provides the manager with incentives to invest in negativeNPV projects. The second component is proportional to firm value and thus reduces the manager's incentives to select a suboptimal investment policy.

When the policy choices of the manager are unconstrained, the manager selects the debt level that best balances these two components. This debt level, denoted by $s_{(\delta)}^{m}$, maximizes

$$
\begin{aligned}
m_{(\delta)}^{\phi}\left(x_{0}, s\right) \equiv & \varphi v_{(\delta)}^{\phi}\left(x_{0}, s\right)+E_{\mathcal{Q}}^{x_{0}}\left[\int_{0}^{T\left(x_{(\delta)}^{l}\right)} e^{-r t}\left(\phi I^{*}+w\right) d t\right] \\
& +\phi E_{\mathcal{Q}}^{x_{0}}\left[\int_{0}^{T\left(x_{(\delta)}^{l}\right)} e^{-r t}\left[\min \left(f_{(\delta)}\left(x_{t}\right)-s, J\right)-I^{*}\right] \mathbf{1}_{f_{(\delta)}\left(x_{t}\right)>s+I^{*}} d t\right]
\end{aligned}
$$

By definition of optimal leverage, we have $v_{(\delta)}^{\phi}\left(x_{0}, s\right) \leq v_{(\delta)}^{\phi}\left(x_{0}, s_{(\delta)}^{*}\right)$ for $s \geq s_{(\delta)}^{*}$. Moreover, the second and third terms on the right-hand side of Equation (14) decrease with s since debt financing constrains the manager's investment policy. Therefore, if there exists a debt service $\mathrm{s}$ such that $m_{(\delta)}^{\phi}(x, s) \geq m_{(\delta)}^{\phi}\left(x, s_{(\delta)}^{*}\right)$, this debt service also satisfies $s \leq s_{(\delta)}^{*}{ }^{16}$

\footnotetext{
${ }^{16}$ The article focuses on the cost of overinvestment associated with internally generated funds. Thus I do not allow managers to finance negative-NPV projects with debt or equity issues. It is important to note, however, that equity issues are not in the standard domain of managerial decisions and require the board's approval. Thus we can assume with little loss in generality that the manager will not raise equity to finance negative-NPV projects. Also, because cash on hand implies greater deviations from value maximization, it may not be optimal for the manager to issue debt to finance negative-NPV projects. In particular, when the risk of a control challenge is high, the optimal policy is to issue debt (to commit to a specific investment policy) and distribute the proceeds from the debt issue as a dividend as part of the commitment strategy [see also Zwiebel (1996)]. In other words, if the manager issues some debt to invest in negative-NPV projects today, investors will expect him to do this also in the future, and hence they will revise their estimate of firm value accordingly. Suppose for instance that at time $t$, cash flows available for investment are less than $I^{*}$. If the manager raises debt in the amount of $J-I^{*}$, he also signals to investors that he will do so in the future to invest in negative-NPV projects until the firm's debt capacity is exhausted. In the base case environment, firm value at the firm's debt capacity is 65 , whereas shareholders' reservation value is 80 . In that case the equilibrium strategy for shareholders is to maintain the manager if he does not issue debt to finance negative-NPV projects and to replace him as soon as he does so. The equilibrium strategy for the manager is to refrain from issuing debt to finance negative NPV. Finally, it is noteworthy that under the assumption that the manager does not raise debt to finance negative-NPV projects, the qualitative predictions of the model are consistent with recent empirical evidence on the relation between managerial entrenchment and leverage. For instance, the model predicts that smaller takeover costs lead to lower leverage [see Garvey and Hanka (1999) for evidence]. In addition, leverage should increase in the aftermath of negative shocks to managerial security [see Berger, Ofek, and Yermak (1997)].
} 
The above argument reveals that without a market for corporate control, the firm generally is underlevered and the empire-building desires of the manager distort its financing and investment policies. Also, according to Equation (14), the debt level selected by the manager balances the utility he derives from investment with the utility he derives from firm value. Therefore the manager may choose to constrain his investment policy, even without a well-functioning market for corporate control.

When the policy choices of the manager erode firm value, the manager can face the threat of a control challenge. The next section analyzes the impact of the market for corporate control on capital structure choices made by the manager.

\subsection{Constrained choice of leverage}

Potential control challenges give the manager an incentive to incorporate the impact of the firm's investment and financing policies on firm value. Specifically, policies that imply larger deviations from value maximization expose the manager to a higher probability of a takeover. Thus the threat of a control challenge raises the cost of empire building and prompts the manager to use debt as a promise that resources will not be squandered [see also Zwiebel (1996)].

The impact of the market for corporate control on the financing policy selected by the manager depends on the opportunity costs faced by investors. These opportunity costs are determined by firm value, with the best alternative management team net of the costs imposed by a control transaction. Within the present model the potential benefits associated with a successful control challenge are determined by the improvement in the target's investment policy. The costs that investors face are determined by (i) the ability of the next-best manager to generate profits from the firm's assets and (ii) out-of-pocket costs, $C$.

If the manager can commit to policy choices that promise investors more value than their next-best alternative, takeovers are effectively precluded. After a successful control challenge, firm value can be expressed as

$$
\begin{aligned}
v_{(1)}^{0}\left(x_{0}, s_{(1)}^{*}\right)= & E_{\mathcal{Q}}^{x_{0}}\left[\int_{0}^{T\left(x_{(1)}^{l}\right)} e^{-r t}(1-\tau)\left(f_{(\delta)}\left(x_{t}\right)+(H-1) I^{*}+\tau s_{(1)}^{*}\right)\right. \\
& \left.+e^{-r T\left(x_{(1)}^{l}\right)} A\left(x_{(1)}^{l}\right) d t\right],
\end{aligned}
$$

where $s_{(1)}^{*}$ is the debt service that maximizes firm value when the operating profits satisfy Equation (3) and $T\left(x_{(1)}^{l}\right)$ is the first passage time of $x_{t}$ to the 
default threshold $x_{(1)}^{l}$. Therefore takeovers can be precluded if there exists a debt service $s$ such that ${ }^{17}$

$$
v_{(\delta)}^{\phi}(x, s) \geq v_{(1)}^{0}\left(x, s_{(1)}^{*}\right)-C .
$$

The following proposition characterizes the financing policy of the firm when the market for corporate control constrains the policy choices of the manager.

Proposition 1. Control challenges can be effectively precluded only if

$$
v_{(\delta)}^{\phi}\left(x, s_{(\delta)}^{*}\right) \geq v_{(1)}^{0}\left(x, s_{(1)}^{*}\right)-C .
$$

When this inequality is satisfied, the manager has some discretion in his policy choices and the financing policy selected by the manager is defined as follows:

(i) When $v_{(\delta)}^{\phi}\left(x, s_{(\delta)}^{m}\right) \geq v_{(1)}^{0}\left(x, s_{(1)}^{*}\right)-C$, the market for corporate control does not affect the policy choices of the manager. In particular, the manager selects the debt level $s_{(\delta)}^{m}$ that maximizes his utility and the empire-building desires of the manager reduce the selected debt level and firm value.

(ii) When $v_{(\delta)}^{\phi}\left(x, s_{(\delta)}^{m}\right)<v_{(1)}^{0}\left(x, s_{(1)}^{*}\right)-C$, there exists a debt service $s \in\left(s_{(\delta)}^{m}, s_{(\delta)}^{*}\right]$ such that $v_{(\delta)}^{\phi}(x, s) \geq v_{(1)}^{0}\left(x, s_{(1)}^{*}\right)-C$. Therefore the threat of a control challenge increases the debt level selected by the manager and improves the firm's investment policy. In the special case where firm value is monotonic over the range $\left(s_{(\delta)}^{m}, s_{(\delta)}^{*}\right]$, the selected debt service $s_{(\delta)}^{A}$ is defined by

$$
s_{(\delta)}^{A}=\inf \left\{s \in\left[s_{(\delta)}^{m}, s_{(\delta)}^{*}\right]: v_{(\delta)}^{\phi}(x, s) \geq v_{(1)}^{0}\left(x, s_{(1)}^{*}\right)-C\right\} .
$$

When the manager faces the threat of a control challenge, the selected debt level results from a trade-off between his empire-building desires and the need to ensure sufficient efficiency to preclude control challenges. Proposition 1 demonstrates that, because of his specific human capital and the costs imposed by control transactions, the manager is partially entrenched. Thus the manager has some discretion in his policy choices and a sufficiently high level of inefficiency is necessary for a control challenge to occur. An equally important result is that debt financing affects not only the value of the firm's investment opportunities, but also the value of assets in place. As a consequence, the degree of managerial entrenchment - and the increase in leverage due to corporate control

\footnotetext{
${ }^{17}$ In this section I consider that control challenges only occur at the time when capital structure is selected. Section 4 presents an extension of the model that incorporates future control challenges.
} 
mechanisms - depend on taxes, costs of financial distress, and the characteristics of the firm's assets in place and investment opportunities.

\section{Numerical results and testable implications}

This section examines the empirical predictions of the model for financing policies. To examine these predictions and determine the various quantities of interest, one needs to solve simultaneously Equations (12), (14), and (18). In addition, it is necessary to specify further the abandonment value of the firm. Following Mello and Parsons (1992), I assume that after default the new owners of the firm continue to employ the assets in their current use, but without issuing debt. Specifically the abandonment value of the firm satisfies

$$
\begin{aligned}
A(x)= & (1-\alpha) \max \left\{E _ { \mathcal { Q } } ^ { x } \left[\int_{0}^{T\left(x_{(1)}^{u}\right)} e^{-r u}(1-\tau)\left(x_{u}-c\right) d u\right.\right. \\
& \left.\left.+e^{-r T\left(x_{(1)}^{u}\right)}(1-\alpha) A\right] ; A\right\},
\end{aligned}
$$

where $\alpha$ represents liquidation costs, $A$ is the liquidation value of the firm's unlevered assets, and $T\left(x_{(1)}^{u}\right)$ is the first passage time of $x_{t}$ to the optimal abandonment threshold $x_{(1)}^{u}$. Input parameter values for the base case are set as follows: ${ }^{18}$ the risk-free interest rate, $r=6 \%$; the differential productivity of the incumbent manager versus the next best alternative, $\delta-1=5 \%$; the initial value of variable cash flows, $x_{0}=5$; the growth rate and volatility of the firm cash flows, $\mu=0.01$ and $\sigma=25 \%$; constant operation costs, $c=1$; the tax advantage of debt, $\tau=15 \%$; bankruptcy costs, $\alpha=25 \%$; the scaled private benefits of the manager, $\phi /$ $\varphi=0.3$; and the liquidation value of the firm's assets, $A=10$. The number of growth options available to the firm is $I^{*}=4$. The return on investment is $H=1.1$ per unit for the first $I^{*}$ units and $L=0.9$ per unit in excess of $I^{*}$. The effects of changing these parameters are also examined.

\subsection{Optimal leverage}

Optimal financing policies have been the focus of previous contingent claim models of the firm. In the present model, the value-maximizing

\footnotetext{
${ }^{18}$ These parameters roughly reflect a typical S\&P 500 firm. The tax advantage of debt captures corporate and personal taxes. The value of the volatility parameter has been chosen to match the volatility of equity returns in the U.S. economy. Using Itô's lemma, this volatility can be computed as vol $($ dele $)=(\partial e / \partial x)$ $(x / e) \sigma$. Bankruptcy costs are at the upper bound of recent estimates by Andrade and Kaplan (1998). Using these parameter values and assuming that the debt has been issued at par, the debtholder bankruptcy recovery rate is $55.9 \%$. This value is consistent with the recovery rate on corporate bonds reported by Hamilton, Gupton, and Berthault (2001) for the period 1981-2000 or by Keenan, Shotgrin, and Sobehart (1999) for the period 1920-1998. Also, the likelihood of default over a 10 -year period is $2.25 \%$, a number which is consistent with the available evidence for default rates on investment-grade bonds [see Brady and Bos (2002)].
} 
debt level $s_{(\delta)}^{*}$ serves as a benchmark against which the manager selects the firm's financing policy. In particular, as shown in Proposition 1, optimal leverage represents an upper bound for actual leverage. Assume that the firm has no growth options and that the manager acts in the best interests of shareholders. (That is, the debt level is set to maximize firm value and $L=1$.) In that case, optimal leverage balances the tax advantage of debt with costs of financial distress. In the base case environment, optimal leverage is equal to $36.4 \%$, where leverage is defined for any debt service $s$ by $l_{(\delta)}(x, s, \phi)=d_{(\delta)}(x, \mathrm{~s}, \phi) / v_{(\delta)}(x, s, \phi)$.

In the presence of agency conflicts, the value-maximizing financing policy also reflects the costs of overinvestment and underinvestment. Consider first that there are no manager-stockholder conflicts $(L=1)$. In that case, the theory predicts that optimal leverage should be lower since, in addition to costs of financial distress, debt induces underinvestment in the firm's growth options. Figure 2a plots optimal leverage as a function of the number of growth options in the firm's investment opportunity set $\left(I^{*}\right)$ and the return on investment for positive-NPV projects $(H)$. The figure shows that optimal leverage decreases with both $I^{*}$ and $H$. Thus underinvestment costs reduce a firm's incentives to issue debt. However, the impact of the cost of underinvestment on optimal leverage is small. The model predicts, for example, that if the NPV of cash flows from the growth options is multiplied by 8 [from $\left(H, I^{*}\right)=(1.05,2)$ to $\left(H, I^{*}\right)=(1.10,8)$ ], optimal leverage decreases from $36.2 \%$ to $35.5 \%$. This result confirms the conjecture made by Parrino and Weisbach (1999) that bondholder-shareholder conflicts are unlikely to explain the low debt levels observed in practice as well as the cross-sectional variation in capital structures.

The limited impact of underinvestment costs on a firm's capital structure choices arises in the present model for two reasons. First, the risk of default is low at optimal leverage and thus underinvestment costs represent a small fraction of firm value (1.32\% in the base case). Second, as firm value increases with the addition of growth options, shareholders revise their default decision, thereby reducing the probability of default. Thus, even though the magnitude of underinvestment costs at the time of default increases with the number of growth options, the change in the expected present value of this cost is small.

Consider next the impact of manager-stockholder conflicts on optimal leverage (i.e., the debt level that maximizes firm value). Figure $2 b$ represents optimal leverage as a function of the number of growth options available to the firm $\left(I^{*}\right)$ and the return on investment per unit in excess of $I^{*}(L)$. All other parameters are set as in the base case environment. Figure $2 \mathrm{~b}$ reveals that manager-stockholder conflicts increase optimal leverage. Of course, the associated increase in leverage depends on the magnitude of deviations from value maximization, that is, on the return on investment per unit in excess of $I^{*}$. In the base case, for example, leverage is $39 \%$. 

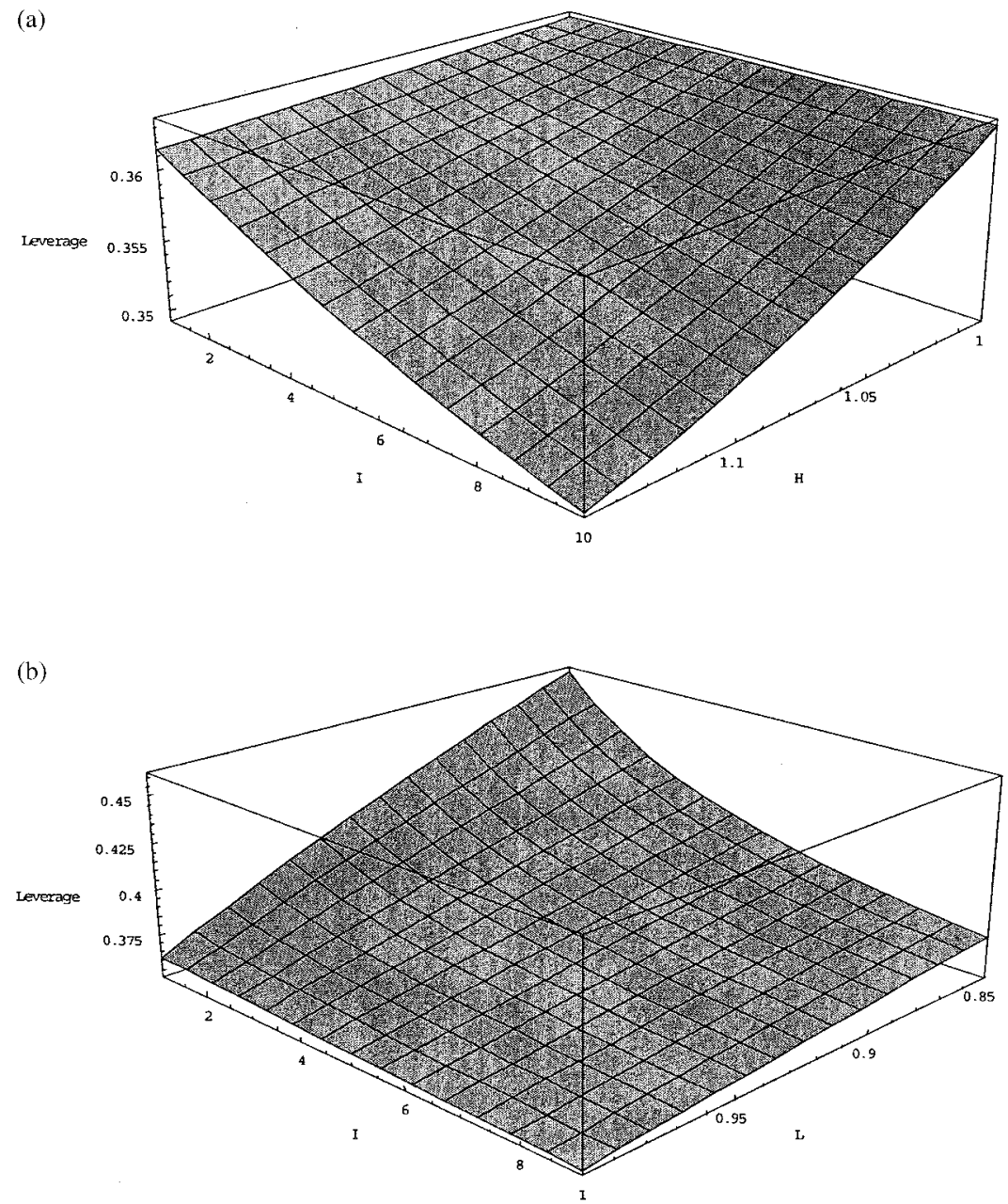

Figure 2

Optimal leverage and agency costs: (a) optimal leverage and underinvestment costs; (b) optimal leverage and overinvestment costs

Plots optimal leverage as a function of the number of growth options available to the firm $\left(I^{*}\right)$ for $I^{*} \in[1,10]$. Input parameter values are set as in the base case environment. Figure $2 \mathrm{a}$ represents the impact of underinvestment costs on optimal leverage for $H \in[1,1.15]$. Figure $2 b$ represents the impact of overinvestment costs on optimal leverage for $L \in[0.85,1]$.

When the number of growth options is $I^{*}=2$ and the return on investment in excess of $I^{*}$ is 0.85 , leverage goes up to $43.5 \%$. Although this result is consistent with the cross-sectional evidence on capital structure (firms with more growth options issue less debt), it reinforces the basic puzzle of why firms do not use more debt. The next section shows that when the manager has discretion over financing policies, 
manager-stockholder conflicts can explain both the low debt levels observed in practice and the cross-sectional evidence on capital structures.

\subsection{Constrained choice of leverage}

Table 1 provides the main comparative statics of the model for the capital structure choices made by entrenched managers. I use three different measures of leverage in this table. The first measure characterizes the financing policy that maximizes firm value $\left(s=s_{(\delta)}^{*}\right)$ and is labeled optimal leverage. The second measure describes the constrained financing policy of the firm $\left(s=s_{(\delta)}^{A}\right)$ and is labeled constrained leverage. The third measure characterizes the financing policy selected by the manager when he makes capital structure decisions in an unconstrained fashion $\left(s=s_{(\delta)}^{m}\right)$ and is labeled unconstrained leverage. Simulation results reported in Table 1 yield several implications. These implications are grouped in three categories as follows.

3.2.1 Leverage levels. The first group of implications relates to the impact of managerial discretion on leverage decisions. Proposition 1 and simulation results reveal that entrenched managers tend to issue less debt than optimal. In the base case environment, for example, optimal leverage is $37 \%$, whereas constrained leverage is $17.61 \%$. Contingent claim models

Table 1

Managerial discretion and leverage decisions

\begin{tabular}{lcccccc}
$\begin{array}{l}\text { Input } \\
\text { parameter } \\
\text { values }\end{array}$ & $\begin{array}{c}\text { Optimal } \\
\text { leverage } \\
l_{(\delta)}^{*}(\%)\end{array}$ & $\begin{array}{c}\text { Constrained } \\
\text { leverage } \\
l_{(\delta)}^{A}(\%)\end{array}$ & $\begin{array}{c}\text { Unconstrained } \\
\text { leverage } \\
l_{(\delta)}^{m}(\%)\end{array}$ & $\begin{array}{c}\text { Actual } \\
\text { value } \\
v_{(\delta)}^{\phi}\left(s_{(\delta)}^{A}\right)\end{array}$ & $\begin{array}{c}\text { Reservation } \\
\text { value } \\
v_{(1)}^{0}-C\end{array}$ & $\begin{array}{c}\text { Equity } \\
\text { volatility } \\
\sigma(d e / e)(\%)\end{array}$ \\
\hline Base & 37.00 & $\mathbf{1 7 . 6 1}$ & 10.01 & 79.88 & 79.88 & 31.20 \\
$\phi / \varphi=0.2$ & 37.00 & $\mathbf{2 1 . 6 2}$ & 21.62 & 80.36 & 79.88 & 32.50 \\
$\phi / \varphi=0.4$ & 37.00 & $\mathbf{1 7 . 6 1}$ & 0 & 79.88 & 79.88 & 31.20 \\
$\delta=1.10$ & 36.86 & $\mathbf{9 . 3 5}$ & 9.35 & 82.75 & 79.88 & 28.69 \\
$\delta=1.02$ & 37.10 & $\mathbf{R}$ & 10.35 & $\mathrm{NA}$ & 79.88 & $\mathrm{NA}$ \\
$x_{0}=4$ & 38.09 & $\mathbf{1 5 . 5 5}$ & 11.52 & 62.61 & 62.61 & 31.34 \\
$x_{0}=6$ & 36.58 & $\mathbf{2 0 . 0 5}$ & 6.07 & 97.21 & 97.21 & 31.44 \\
$\sigma=0.2$ & 41.64 & $\mathbf{1 8 . 8 4}$ & 18.84 & 80.31 & 80.03 & 25.43 \\
$\sigma=0.3$ & 33.65 & $\mathbf{1 9 . 5 9}$ & 4.52 & 80.05 & 80.05 & 37.88 \\
$\mu=0$ & 36.74 & $\mathbf{1 3 . 2 5}$ & 11.03 & 65.58 & 65.58 & 30.21 \\
$\mu=0.02$ & 37.58 & $\mathbf{2 4 . 3 0}$ & 13.70 & 101.64 & 101.64 & 33.15 \\
$\tau=0.25$ & 48.92 & $\mathbf{3 2 . 4 0}$ & 32.40 & 74.32 & 74.19 & 35.58 \\
$\tau=0.10$ & 30.32 & $\mathbf{1 0 . 3 1}$ & 0 & 83.12 & 83.12 & 29.23 \\
$\alpha=0.5$ & 35.00 & $\mathbf{1 5 . 6 1}$ & 6.92 & 79.41 & 79.41 & 30.65 \\
$\alpha=0.1$ & 38.20 & $\mathbf{1 8 . 7 9}$ & 11.82 & 80.17 & 80.17 & 31.48 \\
$I^{*}=5$ & 36.33 & $\mathbf{1 4 . 3 1}$ & 9.61 & 81.23 & 81.23 & 29.85 \\
$I^{*}=3$ & 37.93 & $\mathbf{2 1 . 9 7}$ & 7.04 & 78.54 & 78.54 & 32.98 \\
\end{tabular}

Table 1 reports the main comparative statics concerning leverage decisions made by entrenched managers. I use three measures of leverage in this table. The first measure characterizes the financing policy that maximizes firm value (i.e., $s=s_{(\delta)}^{*}$ ) and is labeled optimal leverage. The second measure characterizes the constrained financing policy of the firm (i.e., $s=s_{(\delta)}^{A}$ ) and is labeled constrained leverage. The third measure characterizes the financing policy selected by the manager when he makes his capital structure decisions in an unconstrained fashion (i.e., $s=s_{(\delta)}^{m}$ ) and is labeled unconstrained leverage. The letter $R$ refers to situations in which the manager is replaced whatever capital structure is selected. 

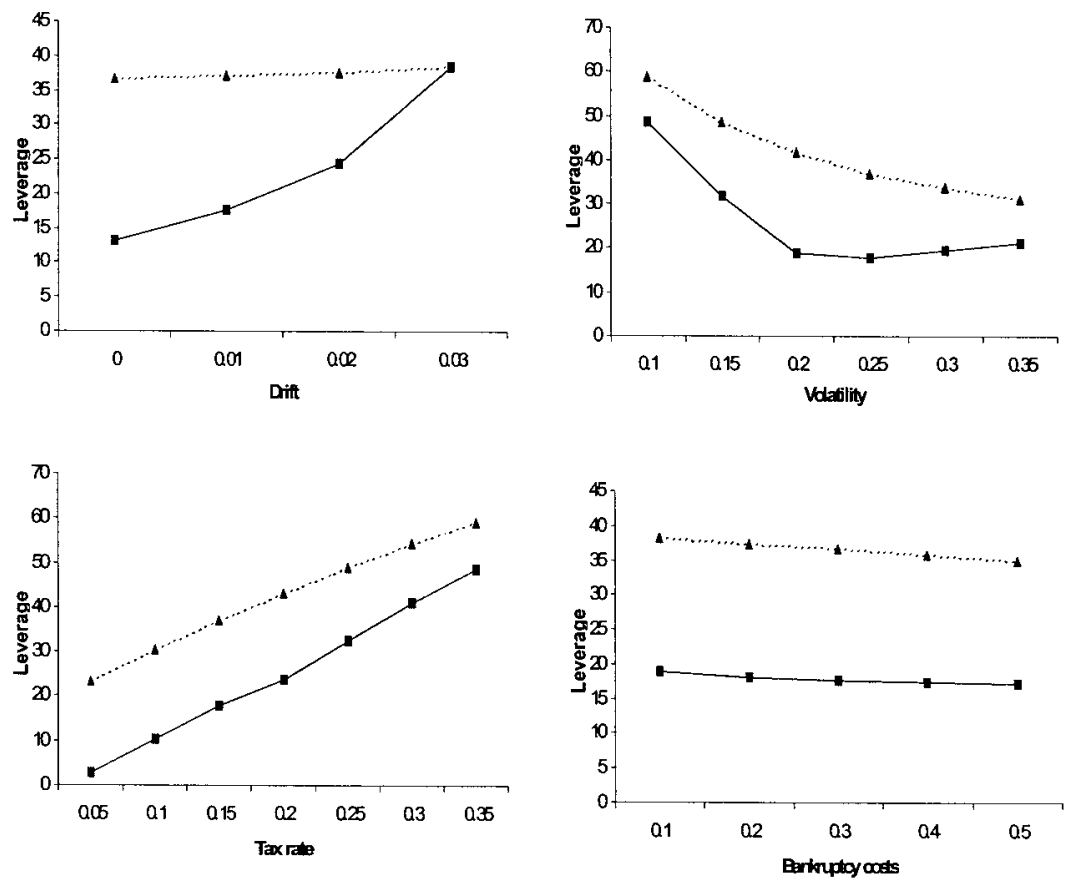

Figure 3

Optimal and constrained leverage ratios

Plots optimal leverage and constrained leverage as functions of (a) the growth rate of cash flows from assets in place; (b) the volatility of cash flows from assets in place; (c) the corporate tax rate $\tau$ and (d) direct bankruptcy costs $\alpha$. Additional input parameter values are set as in the base case environment. The dashed line represents optimal leverage; the solid line represents constrained leverage.

that focus on the trade-off between tax shields and bankruptcy costs usually predict leverage ratios higher than what is typically observed. Data in Table 1 show that the low debt levels observed in practice can be explained by manager-stockholder conflicts. Figure 3, which plots optimal leverage and constrained leverage against several parameters of the model, shows that the impact of manager-stockholder conflicts on leverage decisions varies across firms and generally is significant. Note that the volatility of equity returns in the base case is $31.20 \%,{ }^{19}$ a number which is consistent with what is observed in practice.

Simulation results reported in Table 1 also demonstrate that the threat of a control challenge may prompt managers with a low degree of entrenchment to increase leverage. This is the case in Table 1 whenever

\footnotetext{
${ }^{19}$ The volatility of equity returns acts as a control parameter. For similar levels of volatility in equity returns (and similar tax rates and bankruptcy costs), contingent claim models tend to generate debt ratios which are higher than those observed in practice. For example, leverage ratios range between $60 \%$ and $82 \%$ in Leland (1994) and between $65 \%$ and $82 \%$ in Fan and Sundaresan (2000).
} 
constrained leverage is larger than unconstrained leverage (i.e., when $\left.v_{(\delta)}^{\phi}\left(x, s_{(\delta)}^{A}\right)=v_{(1)}^{0}\left(x, s_{(1)}^{*}\right)-C\right)$. This implication suggests that leverage decisions are related to the degree of managerial entrenchment. Such a relation is documented by Jung, Kim, and Stulz (1996).

Another important implication of data in Table 1 is that capital structure decisions are determined through different channels depending on the firm's environment (i.e., input parameter values). As an illustration, I discuss below the impact of the volatility of cash flows, the growth rate of cash flows, and taxes on leverage decisions.

Volatility and leverage. In contingent claim models, volatility provides a measure of default risk. Typically an increase in volatility raises default risk and hence reduces optimal leverage. This is no longer the case once one introduces manager-stockholder conflicts in the model. In particular, data in Table 1 and Figure 3 reveal that a nonmonotonic relation between leverage and volatility should prevail in such a setting. Specifically, for lower volatility levels, the manager is completely entrenched and the only effect of an increase in volatility is to increase bankruptcy costs. This in turn implies a negative relation between volatility and both optimal and constrained leverage. For higher levels of volatility, an increase in volatility changes not only bankruptcy risk but also the degree of managerial entrenchment. In particular, as volatility increases, expected overinvestment costs increase and hence the debt level necessary to prevent control challenges goes up. Therefore, while optimal leverage continues to decrease with volatility, constrained leverage increases with volatility - inducing a nonmonotonic relation between constrained leverage and volatility. [Morellec and Smith (2002) argue that this phenomenon provides incentives for the manager to engage in hedging transactions.]

Growth rate of cash flows and leverage. Consider next the relation between the growth rate of cash flows and leverage. Data in Table 1 and Figure 3 show that the growth rate of cash flows has little impact on optimal leverage. This result arises because, while a higher growth rate reduces default risk - and thus increases the amount of debt a firm should issue - it is also associated with a higher firm value. In contrast, the growth rate of cash flows has a large impact on constrained leverage. Again, this result is due to the fact that the manager uses debt financing as a defensive device against control challenges. A higher growth rate in cash flows translates into a larger overinvestment cost and hence a larger debt level necessary to prevent control challenges.

Taxes and leverage. Finally, consider the impact of taxes on leverage decisions. When the tax rate is high $(\tau=25 \%)$, the manager has incentives to set leverage at a high level, even without the threat of a control challenge. Indeed, recall from Section 2 that the manager's choice of leverage balances the utility he derives from investment with the utility 
he derives from firm value. Because for low levels of debt, the tax advantage of debt is larger than the costs of debt (bankruptcy costs and control of investment policy), the manager selects a debt level that partially constrains his investment policy. In contrast, when the tax rate is low $(\tau=10 \%)$, the costs of debt exceed the potential gains associated with the tax shield at any debt level. Thus the manager sets (constrained) leverage at the lowest possible level that precludes control challenges.

Simulation results reported in Table 1 underline the impact of the market for corporate control on the firm's leverage decisions. In this table I typically focus on situations in which the manager can preclude control transactions. That is, the manager can use financing policies to commit to an investment policy that will avoid excessive deviations from value maximization and thus eliminate the potential gains associated with a control transaction. However, as shown in Proposition 1, debt financing may not always allow the manager to be immunized against control challenges. Simulation results reveal, for example, that as the growth rate $(\mu)$ or the volatility $(\sigma)$ of cash flows from assets in place increase, expected overinvestment costs increase and hence the ability of the manager to preclude control challenges decreases. In contrast, as the number of growth options increases, potential costs of overinvestment decrease and thus the debt level that precludes control challenges decreases. The next section elaborates on this last point.

3.2.2 Growth options and leverage. Section 3 and data reported in Table 1 show that constrained leverage typically differs from optimal leverage. In particular, the costs imposed by control challenges imply that the manager has some discretion when selecting financing policies. In the present model, the manager values investment more than shareholders do. As a result, debt financing is costly for the manager since it reduces the resources available for investment. Moreover, because more growth options implies less overinvestment, potential gains from a control challenge decrease, and hence managerial discretion increases, as the number of growth options increases. Therefore (constrained) leverage should decrease with the number of growth options available to the firm. This intuition is confirmed by Figure 4, which plots the market value of debt and leverage as a function of the number of growth options available to the firm $\left(I^{*}\right)$. Figure 4 and data in Table 1 reveal that (constrained) leverage decreases as the number of growth options increases, suggesting that manager-stockholder conflicts can explain the cross-sectional evidence on capital structures.

The number of growth options available to the firm has two opposite effects on the market value of corporate debt. First, as the number of 


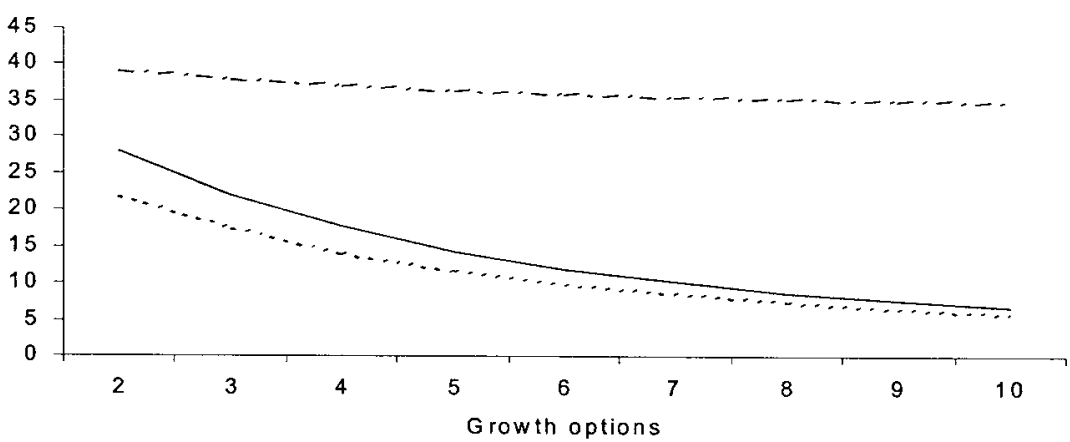

Figure 4

Growth options and financing policies

Plots the market value of debt and the leverage level selected by the manager as a function of the number of growth options in the firm's investment opportunity set for $I^{*} \in[1.2,8]$. For $I^{*}<1.2$, the manager is replaced whatever capital structure is selected. For $I^{*} \geq 1.2$, the financing policy of the manager is constrained by the market for corporate control. Input parameter values are set as in the base case environment. The long- and short-dashed lines represent optimal and constrained leverage, respectively. The solid line represents the market value of corporate debt at the selected leverage ratio.

growth options increases, the size of the debt issue decreases. ${ }^{20}$ Second, for a given face value of debt, default risk decreases with the number of growth options (see Figure 1). Figure 4 shows that the first effect always dominates, although the difference in impact decreases as the number of growth options increases. Therefore the market value of corporate debt describes a decreasing smirk when plotted against the number of positive-NPV projects available to the firm.

3.2.3 Additional implications. The model presented above is a standard principal-agent model in which shareholders delegate policy choices to an empire-building manager. As a result, the model can reproduce a number of predictions already present in this literature.

Managerial entrenchment and changes in leverage. Because capital structure decisions are related to the degree of managerial entrenchment, (unanticipated) shocks to managerial security should induce changes in leverage levels [see Berger, Ofek, and Yermak (1997) for empirical evidence]. For example, the model predicts that a positive shock to the value of the incumbent to the firm should reduce leverage. This shows up in Table 1, where an increase in $\delta$ from 1.05 to 1.10 reduces constrained leverage from $17.61 \%$ to $9.35 \%$. In this light, one can think of leverage and specific human capital as substitutes with respect to the level of managerial entrenchment. (Note, however, that these two factors can have different implications for other policy choices.)

\footnotetext{
${ }^{20}$ This is consistent with the finding in Barclay, Morellec, and Smith (2002) that the debt capacity of growth options is negative.
} 
Stock price changes and leverage changes. Proposition 1 also has implications for equity issues. A (totally unanticipated) positive shock to the value of the incumbent to the firm (an unanticipated increase in $\delta$ ) implies not only an increase in the degree of managerial entrenchment, but also an increase in the market value of the firm. Since the model predicts that increases in $\delta$ should induce equity issues to repurchase debt, it provides a rationale for equity issues following an increase in the firm's stock price or, alternatively, share repurchases following a decease in the firm's stock price. Also, because firms issue less debt than optimal, another implication of the model is that the market should react positively to increases in leverage. Conversely, decreases in leverage should have opposite effects.

Management preferences. As shown in Equation (14), the manager leverage choices balance the benefits he derives from investment (represented by $\phi$ ) with those associated with firm value. As a result, the manager can voluntarily choose a financing policy that constrains his investment policy when his utility is related to firm value (e.g., through compensation policy). This is the case in the simulations whenever the manager selects a debt level that exceeds the one precluding control challenges (i.e., when firm value exceeds its reservation value). For example, when cash flow volatility is $20 \%$ (i.e., $\sigma=0.2$ ), the selected leverage is $18.84 \%$, whereas the debt level that prevents control challenges is $16.79 \%$. Also, as $\phi$ decreases, the manager's incentives become more aligned with shareholders' interests. It is therefore optimal for managers to issue more debt, and the gap between the actual firm value and its reservation value becomes smaller. This shows up in Table 1 , where a decrease of $\phi / \varphi$ from 0.3 to 0.2 increases (constrained) leverage from $17.61 \%$ to $21.62 \%$.

Compensation policy. When determining the optimal level of compensation $\varphi$, it is important to recognize the role of the market for corporate control in constraining management. For example, because of the threat of a control challenge, the minimum debt level in the base case environment is $17.61 \%$. Because in the base case firm value is concave in the coupon level, the incremental gains associated with aligning managerial incentives with shareholders interests are small. Thus it is optimal to set $\varphi$ at the minimum level, ensuring that the utility of the manager under the current contract, $m_{(\delta)}^{\phi}\left(x, s_{(\delta)}^{A}\right)$, is greater than his reservation utility. As the costs of a control transaction and the benefits of debt financing increase, it becomes more valuable to better align managerial incentives at the potential cost of offering the manager more than his reservation utility. This is the case when the corporate tax rate, the cost of overinvestment, or the degree of managerial entrenchment increase. That is, the benefits of better aligning managerial incentives increase with $\tau, \delta, \mu, \sigma$, and $J$, and decrease with $\alpha, H, L$, and $I^{*}$. Suppose, for example, that the differential productivity of the manager is $\delta=1.1$, his fixed compensation is $w=0$, and his 
private benefits are $\phi=0.01$ ( 1 cent per dollar). If the manager is not compensated in stocks, it is optimal (and possible) for the manager to leave the firm unlevered. The policy that maximizes the residual claim of shareholders $\left((1-\varphi) v_{\delta \delta}^{\phi}().\right)$ is then to set $\varphi=4.12 \%$, which increases the leverage ratio selected by the manager to $16.89 \%$. If volatility is increased to $\sigma=30 \%$ (compared to $\sigma=25 \%$ ), it is optimal to set $\varphi=4.30 \%$, which results in a leverage ratio of $13.15 \%$.

Finally, two additional results are worth being mentioned. First, different corporate tax rates and bankruptcy costs are associated with different financing policies. This result obtains not only because the tax advantage of debt trades off bankruptcy costs at a different level, but also because they both affect management's incentives to follow suboptimal policies and shareholders' willingness to constrain management. Second, both leverage and default risk are decreasing in the manager's ability to operate assets in place $(\delta)$. Therefore best-performing firms should exhibit more empire building.

\section{Extensions}

\subsection{Financing constraints and leverage decisions}

The model developed above presumes that, because information is observable, shareholders inject cash whenever the firm cannot finance efficient decisions internally. This assumption implies that underinvestment only occurs if and when the firm defaults on its debt obligations. This section extends the previous analysis to investigate the impact of financing constraints on capital structure decisions. For doing so, I presume that access to external funds is costly (e.g., because of flotation costs) and, for simplicity, model these costs as a constant fraction $\pi$ of the amount raised externally. In addition, I modify the firm's investment opportunity set as follows. I consider that the number of positive-NPV projects per period is $\bar{I}^{*}<J$ and that the payoff from investment is $H>1+\pi$ per unit for the first $\underline{I}^{*}$ units, $\underline{I}^{*}<\bar{I}^{*}$. Investment levels beyond $\underline{I}^{*}$ but less than $\bar{I}^{*}$ yield $h \in(1,1+\pi)$ per unit. Investment levels beyond $\bar{I}^{*}$ but less than $J$ yield $L<1$ per unit. Finally, investment levels beyond $J$ yield zero per unit. ${ }^{21}$ This specification implies that it is optimal for shareholders to inject cash in the firm to finance $\underline{I}^{*}$ units of investment. By contrast, investment levels beyond $\underline{I}^{*}$ have to be financed internally.

\footnotetext{
${ }^{21}$ This specification is consistent with the model of financing constraints described by Froot, Scharfstein, and Stein (1993). In their model, however, financing constraints arise because the costs of raising capital display some convexity and the marginal product of capital is linear.
} 
Under these assumptions, firm value satisfies

$$
\begin{aligned}
v_{(\delta)}^{\phi}\left(x_{0}, s\right)= & E_{\mathcal{Q}}^{x_{0}}\left[\int_{0}^{T\left(x_{(\delta)}^{l}\right)} e^{-r t}\left[(1-\tau) f_{(\delta)}\left(x_{t}\right)+(\tau-\pi) s\right] d t\right] \\
+ & E_{\mathcal{Q}}^{x_{0}}\left[e^{-r T\left(x_{(\delta)}^{l}\right)}(1-\pi) A\left(x_{(\delta)}^{l}\right)\right] \\
+ & E_{\mathcal{Q}}^{x_{0}}\left[\int_{0}^{T\left(x_{(\delta)}^{l}\right)} e^{-r t}(1-\tau)(H-1) \underline{I}^{*} d t\right] \\
& -E_{\mathcal{Q}}^{x_{0}}\left[\int_{0}^{T\left(x_{(\delta)}^{l}\right)} e^{-r t}(1-\tau) \pi\left[\underline{I}^{*}+s-f_{(\delta)}\left(x_{t}\right)\right] \mathbf{1}_{f_{(\delta)}\left(x_{t}\right) \leq s+\underline{I}^{*}} d t\right] \\
+ & E_{\mathcal{Q}}^{x_{0}}\left[\int_{0}^{T\left(x_{(\delta)}^{l}\right)} e^{-r t}(1-\tau)(h-1)\right. \\
& {\left.\left[\min \left(f_{(\delta)}\left(x_{t}\right)-s, \bar{I}^{*}\right)-\underline{I}^{*}\right] \mathbf{1}_{f_{(\delta)}\left(x_{t}\right) \geq s+\underline{I}^{*}} d t\right] } \\
& +E_{\mathcal{Q}}^{x_{0}}\left[\int_{0}^{T\left(x_{(\delta)}^{l}\right)} e^{-r t}(1-\tau)(L-1)\right. \\
& {\left.\left[\min \left(f_{(\delta)}\left(x_{t}\right)-s, J\right)-\bar{I}^{*}\right] \mathbf{1}_{f_{(\delta)}\left(x_{t}\right)>s+\bar{I}^{*}} d t\right] . }
\end{aligned}
$$

The first term on the right-hand side of Equation (19) is the present value of operating cash flows plus the tax savings associated with the debt issue. The second term is the value of the firm upon default discounted between the expected default time and the current date. These first two terms reflect the fact that issuance costs are paid when the debt contract is floated (and the debt contract is issued at par). The fourth term is the present value of recapitalization costs paid by the firm after debt issuance. The third and fifth terms represent the NPV of the first $\bar{I}^{*}$ units of investment. The sixth term accounts for the cost of overinvestment. The solution to this equation is provided in the appendix.

Table 2 describes the impact of growth options on leverage decisions in the presence of financing constraints. ${ }^{22}$ Again, I use three different measures of leverage in this table: optimal leverage for $s=s_{(\delta)}^{*}$, constrained leverage for $s=s_{(\delta)}^{A}$, and managerial leverage for $s=s_{(\delta)}^{m}$. Input parameter values are set as in the base case environment. Additional input parameter values are set as follows. The costs of external resources is equal to $\pi=7 \%$. Investment levels beyond $I *$ but less than $\bar{I}^{*}$ yield a net return of $5 \%$ per unit of capital invested. The number of growth options is given by $I^{*}=4$ and $\bar{I}^{*}=5$.

\footnotetext{
${ }^{22}$ Simulation results for the other parameters (taxes, bankruptcy costs, volatility and drift rate of the state variable, takeover premium, and differential productivity of the incumbent versus the next-best alternative) are similar to those reported in Table 1 and hence are not reported here.
} 
Table 2

Financing constraints and leverage decisions

\begin{tabular}{lcccc}
$\begin{array}{l}\text { Input } \\
\text { parameter } \\
\text { values }\end{array}$ & $\begin{array}{c}\text { Optimal } \\
\text { leverage } \\
l_{(\delta)}^{*}(\%)\end{array}$ & $\begin{array}{c}\text { Constrained } \\
\text { leverage } \\
l_{(\delta)}^{A}(\%)\end{array}$ & $\begin{array}{c}\text { Actual } \\
\text { value } \\
v_{(\delta)}^{\phi}\left(s_{(\delta)}^{A}\right)\end{array}$ & $\begin{array}{c}\text { Reservation } \\
\text { value } \\
v_{(1)}^{0}-C\end{array}$ \\
\hline Base & 30.05 & 12.34 & 78.70 & 75.81 \\
$I^{*}=4, \bar{I}^{*}=6$ & 29.30 & 11.09 & 79.02 & 76.15 \\
$\bar{I}^{*}=4, \bar{I}^{*}=7$ & 28.74 & 10.02 & 79.32 & 76.43 \\
$\bar{I}^{*}=4, \bar{I}^{*}=8$ & 28.31 & 9.29 & 79.56 & 76.66 \\
$\bar{I}^{*}=4, \bar{I}^{*}=9$ & 27.96 & 8.73 & 79.77 & 76.86 \\
$\bar{I}^{*}=5, \bar{I}^{*}=6$ & 29.05 & 5.62 & 78.87 & 76.62 \\
$I^{*}=6, \bar{I}^{*}=7$ & 28.39 & 0 & 79.06 & 77.37 \\
$\bar{I}^{*}=7, \bar{I}^{*}=8$ & 27.78 & 0 & 79.82 & 78.05 \\
$I^{*}=8, \bar{I}^{*}=9$ & 27.33 & 0 & 80.52 & 79.69 \\
\hline
\end{tabular}

Table 2 describes the impact of growth options on leverage decisions in the presence of financing constraints. I use three measures of leverage in this table. The first measure characterizes the financing policy that maximizes firm value (i.e., $s=s_{(\delta)}^{*}$ ) and is labeled optimal leverage. The second measure characterizes the constrained financing policy of the firm (i.e., $s=s_{(\delta)}^{A}$ ) and is labeled constrained leverage. The third measure characterizes the financing policy selected by the manager when he makes his capital structure decisions in an unconstrained fashion (i.e., $s=s_{(\delta)}^{m}$ ) and is labeled unconstrained leverage. Input parameter values are set as in the base case environment. I further presume that the costs of external resources is equal to $\pi=5 \%$, investment levels beyond $I *$ but less than $\bar{I}^{*}$ yield $h=1.05$ per unit, and the number of growth options is given by $\underline{I}^{*}=4$ and $\bar{I}^{*}=\overline{5}$.

Simulation results reported in Table 2 underline two effects of financing constraints on leverage decisions. First, leverage levels decrease with the number of growth options available to the firm. This result again arises in the present model because more growth options implies more underinvestment and less overinvestment. Second, financing constraints reduce both constrained and optimal leverage levels. This second effect is directly illustrated by Figure 5, which represents leverage as a function of the costs of outside funds. (Input parameter values are set as in the base case with $\bar{I}^{*}=6$ and $\left.\pi \in[0.04,0.12]\right)$. As the cost of outside funds increase, the range of projects worth being financed with outside funds decreases and so do shareholders incentives to inject funds in the firm. ${ }^{23}$ As shown in the figure, this effect impacts negatively on both optimal and constrained leverage.

The negative impact of financing constraints on leverage levels arises within the present model for three reasons. First, the regular payments associated with debt financing require the firm to access financial markets more often and hence increase the expected present value of recapitalization costs. Second, debt induces underinvestment in the firm's growth options by reducing the level of internal resources available for investment. Third, because of the greater ability of the incumbent manager to generate cash flows, the degree of managerial discretion with respect to financing policy increases with the level of financing constraints. Data in Table 2 reveal that these effects combine to reduce leverage levels

\footnotetext{
${ }^{23}$ Because of the step function assumption, the cutoff level is at $\pi=H$ in the present model.
} 


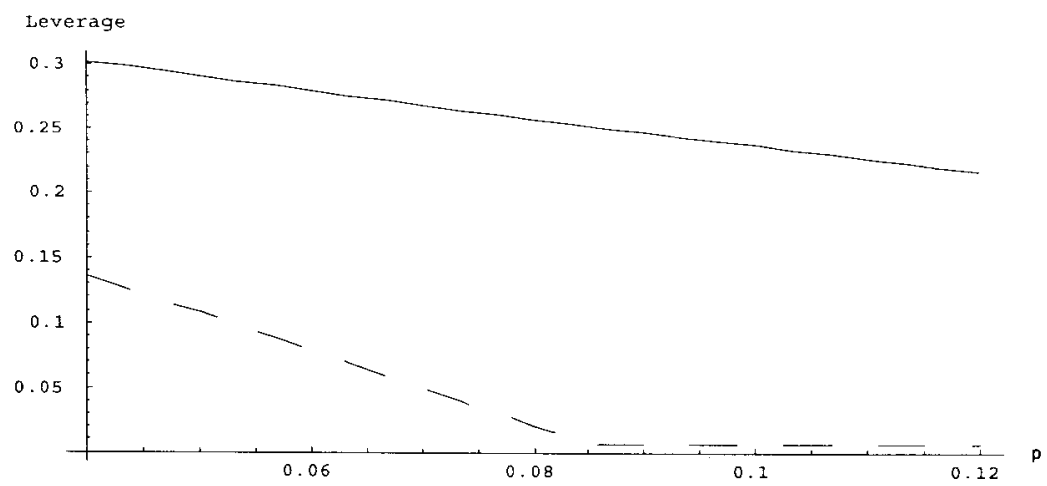

Figure 5

Financing constraints and leverage

Plots optimal leverage and the leverage level selected by the manager as a function of the costs of outside funds for $\pi \in[0.04,0.12], I^{*}=4$, and $\bar{I}^{*}=6$. Input parameter values are set as in the base case environment. The dashed line represents constrained leverage. The solid line represents optimal leverage.

in comparison with Table 1. It is also interesting to note that the first of these three effects seems to be the most important quantitatively. Indeed, as illustrated in Table 2, the impact of recapitalization costs on leverage decisions is larger for those firms that have a larger number of profitable projects, that is, firms that will more often have incentives to access financial markets.

\subsection{Future control challenges}

In order to keep the analysis simple, I have considered a setting in which a takeover either occurs at the outset or can never occur. In this section I consider a more general framework in which the manager's choice of leverage reflects both immediate and future control challenges. ${ }^{24}$

By definition, the takeover surplus is equal to

$$
v_{(1)}^{0}\left(x, s_{(1)}^{*}\right)-v_{(\delta)}^{\phi}(x, s)-C .
$$

Because this takeover surplus is uncertain and the costs associated with the takeover are sunk, outside investors have an option to take over the target firm. I consider in what follows that competition drives the option value of waiting to zero so that a takeover is realized for $x=x^{T}(s)$, where

$$
x^{T}(s)=\inf \left\{x>0: v_{(1)}^{0}\left(x, s_{(1)}^{*}\right)-v_{(\delta)}^{\phi}(x, s)-C \geq 0\right\} .
$$

To ensure that this level for the state variable exists (and is finite), I presume thereafter that $\delta L<1$ and I let $J \rightarrow \infty$. Now, let $t$ denote the

\footnotetext{
${ }^{24} \mathrm{I}$ thank an anonymous referee for suggesting this section.
} 
current time, suppose that $x_{t} \in\left(x_{(\delta)}^{l}, x^{T}(s)\right)$ and define the following random variables:

$$
\begin{aligned}
T\left(x_{(\delta)}^{l}\right) & \equiv \inf \left\{u>t: x_{u}=x_{(\delta)}^{l}\right\}, \\
T\left(x^{T}(s)\right) & \equiv \inf \left\{u>t: x_{u}=x^{T}(s)\right\}, \\
T & \equiv T\left(x_{(\delta)}^{l}\right) \wedge T\left(x^{T}(s)\right) .
\end{aligned}
$$

$T$ represents the first time the manager loses control of the firm. This loss of control can arise either because of default $\left(T=T\left(x_{(\delta)}^{l}\right)\right)$ or because of a takeover $\left(T=T\left(x^{T}(s)\right)\right)$.

In this setting the manager selects the debt level that best balances the risk of a control challenge and the risk of default. This debt level, denoted by $s_{(\delta)}^{m}$, maximizes

$$
\begin{aligned}
m_{(\delta)}^{\phi}\left(x_{0}, s\right) \equiv & \varphi v_{(\delta)}^{\phi}\left(x_{0}, s\right) \\
& +\phi E_{\mathcal{Q}}^{x_{0}}\left[\int_{0}^{T} e^{-r t}\left[I^{*}+\left(f_{(\delta)}\left(x_{t}\right)-s-I^{*}\right) \mathbf{1}_{f_{(\delta)}\left(x_{t}\right)>s+I^{*}}\right] d t\right],
\end{aligned}
$$

where firm value satisfies

$$
\begin{aligned}
v_{(\delta)}^{\phi}\left(x_{0}, s\right)= & E_{\mathcal{Q}}^{x_{0}}\left[\int_{0}^{T} e^{-r t}\left[(1-\tau) f_{(\delta)}\left(x_{t}\right)+\tau s+(1-\tau)(H-1) I^{*}\right] d t\right] \\
& +E_{\mathcal{Q}}^{x_{0}}\left[\int_{0}^{T} e^{-r t}(1-\tau)(L-1)\left[f_{(\delta)}\left(x_{t}\right)-s-I^{*}\right] \mathbf{1}_{f_{(\delta)}\left(x_{t}\right)>s+I^{*}} d t\right] \\
& +E_{\mathcal{Q}}^{x_{0}}\left[e^{-r T\left(x^{T}(s)\right)} \mathbf{1}_{T\left(x^{T}(s)\right)<T\left(x_{(\delta)}^{l}\right)}\left(v_{(1)}^{0}\left(x^{T}(s), s_{(1)}^{*}\right)-C\right)\right] \\
& +E_{\mathcal{Q}}^{x_{0}}\left[e^{-r T\left(x_{(\delta)}^{l}\right)} \mathbf{1}_{T\left(x_{(\delta)}^{l}\right)<T\left(x^{T}(s)\right)} A\left(x_{(\delta)}^{l}\right)\right] .
\end{aligned}
$$

Equation (21) shows that firm value is equal to the expected present value of the cash flows generated until the control change (the first two terms on the right-hand side), plus the value accruing to stakeholders at the time of the change of control. This value is equal to the abandonment value of the firm in case of default or to firm value in case of a takeover. (The solution to this equation is provided in the appendix.) In addition, the default threshold selected by shareholders maximizes the value of equity given by

$$
\begin{aligned}
e_{(\delta)}^{\phi}\left(x_{0}, s\right)= & E_{\mathcal{Q}}^{x_{0}}\left[\int_{0}^{T} e^{-r t}(1-\tau)\left(f_{(\delta)}\left(x_{t}\right)+(H-1) I^{*}-s\right) d t\right] \\
& +E_{\mathcal{Q}}^{x_{0}}\left[\int_{0}^{T} e^{-r t}(1-\tau)(L-1)\left[f_{(\delta)}\left(x_{t}\right)-s-I^{*}\right] \mathbf{1}_{f_{(\delta)}\left(x_{t}\right)>s+I^{*}} d t\right] \\
& +E_{\mathcal{Q}}^{x_{0}}\left[e^{-r T\left(x^{T}(s)\right)} \mathbf{1}_{T\left(x^{T}(s)\right)<T\left(x_{(\delta)}^{l}\right)}\left(v_{(1)}^{0}\left(x^{T}(s), s_{(1)}^{*}\right)-C\right)\right] .
\end{aligned}
$$


Table 3

Future control challenges and leverage decisions

\begin{tabular}{|c|c|c|c|}
\hline $\begin{array}{l}\text { Input } \\
\text { parameter } \\
\text { value }\end{array}$ & $\begin{array}{c}\text { Constrained } \\
\text { leverage } \\
l_{(\delta)}^{A}(\%)\end{array}$ & $\begin{array}{l}\text { Actual } \\
\text { value } \\
v_{(\delta)}^{\phi}\left(s_{(\delta)}^{A}\right)\end{array}$ & $\begin{array}{c}\text { Reservation } \\
\text { value } \\
v_{(1)}^{0}-C\end{array}$ \\
\hline Base & 30.47 & 81.53 & 79.88 \\
\hline$\phi / \varphi=0.05$ & 34.93 & 81.86 & 79.88 \\
\hline$\phi / \varphi=0.15$ & 25.53 & 81.08 & 79.88 \\
\hline$\delta=1.07$ & 27.30 & 82.09 & 79.88 \\
\hline$\delta=1.03$ & 41.79 & 82.35 & 79.88 \\
\hline$x_{0}=4$ & 27.40 & 63.86 & 62.61 \\
\hline$x_{0}=6$ & 35.20 & 99.58 & 97.21 \\
\hline$\sigma=0.2$ & 35.35 & 82.15 & 80.03 \\
\hline$\sigma=0.3$ & 34.20 & 81.94 & 80.05 \\
\hline$\mu=0$ & 23.92 & 66.77 & 65.58 \\
\hline$\mu=0.02$ & 35.15 & 105.80 & 101.64 \\
\hline$I^{*}=5$ & 28.05 & 82.96 & 81.43 \\
\hline$I^{*}=3$ & 35.30 & 80.29 & 78.54 \\
\hline
\end{tabular}

Table 3 reports the main comparative statics concerning leverage decisions made by entrenched managers when leverage choices reflect the possibility of a future control challenge. Input parameter values are set as in the base case environment.

Table 3 describes the impact of potential future control challenges on leverage choices made by entrenched managers. Simulation results reported in this table underline two effects of future control challenges on the quantities of interest. First, in response to the increase in the risk of a control challenge, the manager selects a higher leverage ratio. In particular, leverage increases from $17.61 \%$ to $30.47 \%$ in the base case environment. ${ }^{25}$ Second, the increase in the selected leverage ratio raises firm value and increases the costs of an immediate control challenge.

It is also important to note that the comparative statics for this (more general) model are similar to those of the (basic) model presented above. In particular, the degree of managerial entrenchment increases with the differential productivity of the incumbent manager versus the next-best alternative $\delta$ and the number of growth options $I^{*}$ available to the firm and decreases with the growth rate of cash flows $\mu$, cash flow volatility $\sigma$, and the initial level of cash flows $x_{0}$. Therefore selected leverage ratios increase with $\mu, \sigma$, and $x_{0}$, and decrease with $\delta$ and $I^{*}$. Finally, because the manager's incentives get more aligned with shareholders' interest as $\phi$ decreases, leverage ratios decrease with the private benefits the manager extracts from investment.

\footnotetext{
${ }^{25}$ Because the manager cannot (by assumption) change the firm's leverage ratio in the future, the leverage ratios reported in Table 3 may exceed those that would be generated in a dynamic capital structure model. See Goldstein, Ju, and Leland (2001) and Titman and Tsyplakov (2002) for a discussion of leverage choices in dynamic versus static models when managers act in the best interest of shareholders.
} 


\section{Conclusion}

Since Jensen and Meckling (1976), a large fraction of the corporate finance literature has analyzed the interaction between investment and financing policies. Two commonly discussed conflicts of interest arising from this interaction are stockholder-bondholder conflicts and managerstockholder conflicts. Several authors have argued that stockholderbondholder conflicts might explain both the low debt levels observed in practice and the cross-sectional evidence on capital structure [see Smith and Watts (1992) and Rajan and Zingales (1995)]. Recent work, however, has cast some doubt on their ability to explain capital structure choices [see Leland (1998) and Parrino and Weisbach (1999)].

This article analyzes the impact of manager-stockholder conflicts on leverage and firm value in a contingent claims model where the manager derives perquisites from investment. The model determines both the magnitude of the agency costs of managerial discretion and the impact of these costs on leverage decisions. The analysis shows that manager-shareholder conflicts can explain both the low debt levels observed in practice and the fact that high growth options firms tend to use less debt. The article also provides a number of comparative statics that emphasize the interaction among the many determinants of leverage choices. These determinants include taxes, costs of financial distress, the market for corporate control, the volatility of cash flows from assets in place, and the profitability of the firm's current operations. The comparative statics suggest that the impact of managerial discretion on leverage choices varies extensively across firms and generally is substantial.

The analysis in the article follows most of the literature by presuming that the firm's leverage level is fixed once and for all by the manager. Adopting this assumption allows for simple, intuitive expressions for the values of corporate securities. One interesting extension of the present model would be to consider dynamic leverage changes in the presence of manager-stockholder conflicts. The analysis in the article demonstrates that as economic conditions change, both optimal and constrained leverage are affected. In particular, constrained leverage converges to optimal leverage as the degree of managerial entrenchment decreases. Moreover, at the time of a takeover, constrained leverage equals optimal leverage, whereas firm value equals its running maximum. For the analysis of dynamic leverage to be nontrivial (and for takeovers to occur), one would need to incorporate frictions such as transaction costs. However, when frictions are taken into account, the determination of dynamic leverage in the presence of manager-stockholder conflicts is a complex problem since the manager's objective is not to maximize firm value, but instead to maximize his utility while preventing control challenges. 


\section{Appendix}

A.1 Value of the unlevered firm for $f_{(\delta)}\left(x_{0}\right) \leq I^{*}$

The value of the unlevered firm is given by

$$
\begin{aligned}
\nu_{(\delta)}^{\phi}\left(x_{0}\right)= & E_{\mathcal{Q}}^{x_{0}}\left[\int_{0}^{T\left(x_{(\delta)}^{u}\right)} e^{-r t}(1-\tau) f_{(\delta)}\left(x_{t}\right) d t\right]+E_{\mathcal{Q}}^{x_{0}}\left[e^{-r T\left(x_{(\delta)}^{u}\right)} A\left(x_{(\delta)}^{u}\right)\right] \\
& +E_{\mathcal{Q}}^{x_{0}}\left[\int_{0}^{T\left(x_{(\delta)}^{u}\right)} e^{-r t}(1-\tau)\left[(H-1) I^{*}+(L-1)\left(J-I^{*}\right) \mathbf{1}_{f\left(x_{t}\right) \geq J}\right] d t\right] \\
& +E_{\mathcal{Q}}^{x_{0}}\left[\int_{0}^{T\left(x_{(\delta)}^{u}\right)} e^{-r t}(1-\tau)(L-1)\left[f_{(\delta)}\left(x_{t}\right)-I^{*}\right] \mathbf{1}_{I^{*}<f_{(\delta)}\left(x_{t}\right)<J} d t\right] .(23)
\end{aligned}
$$

Using standard results concerning Brownian motion [see Karatzas and Shreve (1991)], the first three terms of the right-hand side of this equation can be computed as

$$
\begin{aligned}
E_{\mathcal{Q}}^{x_{0}}\left[\int_{0}^{T\left(x_{(\delta)}^{u}\right)} e^{-r t} f_{(\delta)}\left(x_{t}\right) d t\right] & =\frac{\delta x_{0}}{r-\mu}-\frac{c}{r}-\left(\frac{\delta x_{(\delta)}^{u}}{r-\mu}-\frac{c}{r}\right)\left(\frac{x_{0}}{x_{(\delta)}^{u}}\right)^{\vartheta} \\
E_{\mathcal{Q}}^{x_{0}}\left[e^{-r T\left(x_{(\delta)}^{u}\right)} A\left(x_{(\delta)}^{u}\right)\right] & =A\left(x_{(\delta)}^{u}\right)\left(\frac{x_{0}}{x_{(\delta)}^{u}}\right)^{\vartheta} \\
E_{\mathcal{Q}}^{x_{0}}\left[\int_{0}^{T\left(x_{(\delta)}^{u}\right)} e^{-r t}(H-1) I^{*} d t\right] & =\frac{(H-1) I^{*}}{r}\left[1-\left(\frac{x_{0}}{x_{(\delta)}^{u}}\right)^{\vartheta}\right] .
\end{aligned}
$$

Consider next the fourth term. Using the equality $\mathbf{1}_{I^{*}<f(\delta)(x t)<J}=\mathbf{1}_{f(\delta)\left(x_{t}\right)>I^{*}}-\mathbf{1}_{f_{(\delta)}\left(x_{t}\right)>J}$, this term can be decomposed into

$$
E_{\mathcal{Q}}^{x_{0}}\left[\int_{0}^{T_{x a}} e^{-r t}(L-1)\left(f_{(\delta)}\left(x_{t}\right)-I^{*}\right)\left(\mathbf{1}_{f_{(\delta)}\left(x_{t}\right)>I^{*}}-\mathbf{1}_{f_{(\delta)}\left(x_{t}\right)>J}\right) d t\right] .
$$

Now, we can also write

$$
\begin{aligned}
& E_{\mathcal{Q}}^{x_{0}}\left[\int_{0}^{T\left(x_{(\delta)}^{u}\right)} e^{-r t}\left(f_{(\delta)}\left(x_{t}\right)-I^{*}\right) \mathbf{1}_{f(\delta)}\left(x_{t}\right)>I^{*}\right. \\
& d t]=\delta E_{\mathcal{Q}}^{x_{0}}\left[\int_{0}^{T\left(x_{(\delta)}^{u}\right)} e^{-r t} x_{t} \mathbf{1}_{f(\delta)}\left(x_{t}\right)>I^{*} d t\right] \\
& -\left(c+I^{*}\right) E_{\mathcal{Q}}^{x_{0}}\left[\int_{0}^{T\left(x_{(\delta)}^{u}\right)} e^{-r t} \mathbf{1}_{f_{(\delta)}\left(x_{t}\right)>I^{*}} d t\right] .
\end{aligned}
$$

Consider the first integral on the right $\left\{\left\lfloor\right.\right.$ hbox $\{-\}$ hand side of Equation (28). Writing $Z_{t}^{b}=$ $Z_{t}+b t$ with $b=(1 / \sigma)\left(\mu-\sigma^{2} / 2\right)$ and $a=(1 / \sigma) \ln \left(c+I^{*} / \delta x_{0}\right)$ gives

$$
\delta E_{\mathcal{Q}}^{x_{0}}\left[\int_{0}^{T\left(x_{(\delta)}^{u}\right)} e^{-r t} x_{t} \mathbf{1}_{f_{(\delta)}\left(x_{t}\right)>I^{*}} d t\right]=\delta x_{0} E_{\mathcal{Q}}^{x_{0}}\left[\int_{0}^{T\left(Z_{(\delta)}^{u}\right)} e^{-r t} e^{\sigma Z_{t}^{b}} \mathbf{1}_{Z_{t}^{b}>a} d t\right],
$$

where $Z_{(\delta)}^{u}=(1 / \sigma) \ln \left(x_{(\delta)}^{u} / x_{0}\right)$ and

$$
T\left(Z_{(\delta)}^{u}\right)=\inf \left\{t \geq 0: Z_{t}^{b}=Z_{(\delta)}^{u}\right\}
$$


Applying the Cameron-Martin-Girsanov theorem with

$$
\forall t \geq 0,\left.\quad \frac{d \mathcal{Q}}{d \mathcal{P}}\right|_{\mathcal{F}_{t}}=e^{b Z_{t}-\left(b^{2} / 2\right) t}
$$

yields

$$
\delta x_{0} E_{\mathcal{P}}^{x_{0}}\left[\int_{0}^{+\infty} e^{(\sigma+b) Z_{t}^{b}} e^{-\left(\lambda^{2} / 2\right) t} \mathbf{1}_{Z_{t}^{b}>a} d t\right]-\delta x_{0} E_{\mathcal{P}}^{x_{0}}\left[\int_{T\left(Z_{(\delta)}^{u}\right)}^{+\infty} e^{(\sigma+b) Z_{t}^{b}} e^{-\left(\lambda^{2} / 2\right) t} \mathbf{1}_{Z_{t}^{b}>a} d t\right],
$$

where $\lambda=\sqrt{2 r+b^{2}}$ and $\left(Z_{t}^{b}, t \geq 0\right)$ is a standard Brownian motion under $\mathcal{P}$. To compute these integrals I use the following lemma [see Karatzas and Shreve (1991, p. 272)].

Lemma 2. If $f: \mathbb{R} \rightarrow \mathbb{R}$ is a piecewise continuous function with

$$
\int_{-\infty}^{+\infty}|f(x+y)| e^{-|y| \sqrt{2 \gamma}} d y<\infty ; \quad \forall x \in \mathbb{R}
$$

for some constant $\gamma>0$, and $\left(Z_{t}, t \geq 0\right)$ is a standard Brownian motion, the resolvent operator of Brownian motion $K_{\gamma}(f)$ is defined by

$$
K_{\gamma}(f) \equiv E\left[\int_{0}^{+\infty} e^{-\gamma t} f\left(Z_{t}\right) d t\right]=\frac{1}{\sqrt{2 \gamma}} \int_{-\infty}^{+\infty} f(y) e^{-|y| \sqrt{2 \gamma}} d y
$$

Using the above lemma and the strong Markov property of Brownian motion, the second expectation in Equation (31) can be computed as follows:

$$
\begin{aligned}
& \delta x_{0} E_{\mathcal{P}}^{x_{0}}\left[\int_{T\left(Z_{(\delta)}^{u}\right)}^{+\infty} e^{(\sigma+b) Z_{t}^{b}} e^{-\left(\lambda^{2} / 2\right) t} \mathbf{1}_{Z_{t}^{b}>a} d t\right] \\
& =\delta x_{0} E_{\mathcal{P}}^{x_{0}}\left[e^{-\left(\lambda^{2} / 2\right) T\left(Z_{(\delta)}^{u}\right)} \int_{0}^{+\infty} e^{(\sigma+b)\left(Z_{t}^{b}+Z_{(\delta)}^{u}\right)} e^{-\left(\lambda^{2} / 2\right) t} \mathbf{1}_{Z_{t}^{b}>a-Z_{(\delta)}^{u}} d t\right] \\
& =\delta x_{0} e^{(\sigma+b) Z_{(\delta)}^{u}-\left|Z_{(\delta)}^{u}\right| \lambda} E_{\mathcal{P}}^{x_{0}}\left[\int_{0}^{+\infty} e^{(\sigma+b) Z_{t}^{b}} e^{-\left(\lambda^{2} / 2\right) t} \mathbf{1}_{Z_{t}^{b}>a-Z_{(\delta)}^{u}} d t\right] \\
& =\frac{\delta x_{0}}{\lambda} e^{(\sigma+b) Z_{(\delta)}^{u}-\left|Z_{(\delta)}^{u}\right| \lambda} \int_{a-Z_{(\delta)}^{u}}^{+\infty} e^{-|y| \lambda} e^{(\sigma+b) y} d y \\
& =\frac{c+I^{*}}{\lambda(\lambda-\sigma-b)}\left(\frac{x_{0}}{x_{(\delta)}^{u}}\right)^{\vartheta}\left(\frac{\delta x_{(\delta)}^{u}}{c+I^{*}}\right)^{\xi},
\end{aligned}
$$

where $b=\left(\mu-\sigma^{2} / 2\right) / \sigma, \lambda=\sqrt{2 r+b^{2}}, \vartheta=-(b+\lambda) / \sigma$, and $\xi=(\lambda-b) / \sigma$.

Similar calculations yield

$$
\delta x_{0} E_{\mathcal{P}}^{x_{0}}\left[\int_{0}^{+\infty} e^{(\sigma+b) Z_{t}^{b}} e^{-\left(\lambda^{2} / 2\right) t} \mathbf{1}_{Z_{t}^{b}>a} d t\right]=\frac{c+I^{*}}{\lambda(\lambda-\sigma-b)}\left(\frac{\delta x_{0}}{c+I^{*}}\right)^{\xi},
$$

Combining these two equations gives

$$
\delta E_{\mathcal{P}}^{x_{0}}\left[\int_{0}^{T\left(x_{(\delta)}^{u}\right)} e^{-r t} x_{t} \mathbf{1}_{f_{(\delta)}\left(x_{t}\right)>I^{*}} d t\right]=\frac{c+I^{*}}{\lambda(\lambda-\sigma-b)}\left(\frac{\delta x_{0}}{c+I^{*}}\right)^{\xi}\left[1-\left(\frac{x_{0}}{x_{(\delta)}^{u}}\right)^{\vartheta-\xi}\right] .
$$


The second term in Equation (28) is

$$
E_{\mathcal{P}}^{x_{0}}\left[\int_{0}^{T\left(x_{(\delta)}^{u}\right)} e^{-r t} \mathbf{1}_{f_{(\delta)}\left(x_{t}\right)>I^{*}} d t\right]=\frac{1}{\lambda(\lambda-b)}\left(\frac{\delta x_{0}}{c+I^{*}}\right)^{\xi}\left[1-\left(\frac{x_{0}}{x_{(\delta)}^{u}}\right)^{\vartheta-\xi}\right] .
$$

Therefore Equation (27) reduces to

$$
E_{\mathcal{P}}^{x_{0}}\left[\int_{0}^{T\left(x_{(\delta)}^{u}\right)} e^{-r t}\left(f_{(\delta)}\left(x_{t}\right)-I^{*}\right) \mathbf{1}_{f_{(\delta)}\left(x_{t}\right)>I^{*}} d t\right]=\frac{\sigma\left(c+I^{*}\right)^{1-\xi}\left(\delta x_{0}\right)^{\xi}}{\lambda(\lambda-\sigma-b)(\lambda-b)}\left[1-\left(\frac{x_{0}}{x_{(\delta)}^{u}}\right)^{\vartheta-\xi}\right] .
$$

Similarly we have

$$
E_{\mathcal{P}}^{x_{0}}\left[\int_{0}^{T\left(x_{(\delta)}^{u}\right)} e^{-r t}\left(f_{(\delta)}\left(x_{t}\right)-J\right) \mathbf{1}_{f_{(\delta)}\left(x_{t}\right)>J} d t\right]=\frac{\sigma(c+J)^{1-\xi}\left(\delta x_{0}\right)^{\xi}}{\lambda(\lambda-\sigma-b)(\lambda-b)}\left[1-\left(\frac{x_{0}}{x_{(\delta)}^{u}}\right)^{v-\xi}\right],
$$

and the value of the unlevered firm satisfies for $f_{(\delta)}\left(x_{0}\right) \leq I^{*}$ :

$$
\begin{aligned}
v_{(\delta)}^{\phi}\left(x_{0}\right)= & (1-\tau)\left(\frac{\delta x_{0}}{r-\mu}-\frac{c}{r}\right)-(1-\tau)\left(\frac{\delta x_{(\delta)}^{u}}{r-\mu}-\frac{c}{r}\right)\left(\frac{x_{0}}{x_{(\delta)}^{u}}\right)^{\vartheta} \\
& +A\left(x_{(\delta)}^{u}\right)\left(\frac{x_{0}}{x_{(\delta)}^{u}}\right)^{\vartheta}+\frac{(1-\tau)(H-1) I^{*}}{r}\left[1-\left(\frac{x_{0}}{x_{(\delta)}^{u}}\right)^{\vartheta}\right] \\
& +\frac{(1-\tau)(L-1) \sigma\left[\left(c+I^{*}\right)^{1-\xi}-(c+J)^{1-\xi}\right]}{\lambda(\lambda-\sigma-b)(\lambda-b)\left(\delta x_{0}\right)^{-\xi}}\left[1-\left(\frac{x_{0}}{x_{(\delta)}^{u}}\right)^{\vartheta-\xi}\right] .
\end{aligned}
$$

\section{A.2 Value of the unlevered firm when $I^{*} \leq f_{(\delta)}\left(x_{0}\right) \leq J$}

The value of the unlevered firm is given by Equation (23). Because the firm's investment policy depends on the level of resources generated by the firm's assets, so does firm value. In particular, when $f_{(\delta)}\left(x_{0}\right) \geq I^{*}$ the firm is currently overinvesting. By contrast, when $f_{(\delta)}\left(x_{0}\right)<I^{*}$, the manager does not currently have enough resources to invest in negative-NPV projects. This implies that the firm's investment policy depends on the contemporaneous level of cash flows, and so does the solution for firm value. In particular, when $I^{*} \leq f_{(\delta)}\left(x_{0}\right) \geq J$, firm value satisfies

$$
\begin{aligned}
v_{(\delta)}^{\phi}\left(x_{0}\right)= & (1-\tau) L\left(\frac{\delta x_{0}}{r-\mu}-\frac{c}{r}\right)-(1-\tau)\left(\frac{\delta x_{(\delta)}^{u}}{r-\mu}-\frac{c}{r}\right)\left(\frac{x_{0}}{x_{(\delta)}^{u}}\right)^{\vartheta} \\
& +\frac{(1-\tau)(H-L) I^{*}}{r}-\frac{(1-\tau)(H-1) I^{*}}{r}\left(\frac{x_{0}}{x_{(\delta)}^{u}}\right)^{\vartheta}+A\left(x_{(\delta)}^{u}\right)\left(\frac{x_{0}}{x_{(\delta)}^{u}}\right)^{\vartheta} \\
& +\frac{(1-\tau)(L-1) \sigma\left(c+I^{*}\right)}{\lambda(\lambda+\sigma+b)(\lambda+b)}\left(\frac{\delta x_{0}}{c+I^{*}}\right)^{\vartheta}-\frac{(1-\tau)(L-1) \sigma(c+J)}{\lambda(\lambda-\sigma-b)(\lambda-b)}\left(\frac{\delta x_{0}}{c+J}\right)^{\xi} \\
& -\frac{(1-\tau)(L-1) \sigma\left[\left(c+I^{*}\right)^{1-\xi}-(c+J)^{1-\xi}\right]}{\lambda(\lambda-\sigma-b)(\lambda-b)\left(\delta x_{0}\right)^{-\xi}}\left(\frac{x_{0}}{x_{(\delta)}^{u}}\right)^{\vartheta-\xi} .
\end{aligned}
$$

Using the relations

$$
\frac{1}{r-\mu}=\frac{1}{\lambda}\left[\frac{1}{\lambda+\sigma+b}+\frac{1}{\lambda-\sigma-b}\right] \text { and } \frac{1}{r}=\frac{1}{\lambda}\left[\frac{1}{\lambda+b}+\frac{1}{\lambda-b}\right] \text {, }
$$


it is possible to verify that the two equations, Equations (39) and (40), for the value of the unlevered firm are equivalent when $f_{(\delta)}\left(x_{0}\right)=I^{*}$.

\section{A.3 Value of the levered firm}

The value of the levered firm is given by

$$
\begin{array}{r}
v_{(\delta)}^{\phi}\left(x_{0}, s\right)=E_{\mathcal{Q}}^{x_{0}}\left[\int_{0}^{T\left(x_{(\delta)}^{l}\right)} e^{-r t}\left((1-\tau) f_{(\delta)}\left(x_{t}\right)+\tau s\right) d t+e^{-r T\left(x_{(\delta)}^{l}\right)} A\left(x_{(\delta)}^{l}\right)\right] \\
+E_{\mathcal{Q}}^{x_{0}}\left[\int_{0}^{T\left(x_{(\delta)}^{l}\right)} e^{-r t}(1-\tau)\left[(H-1) I^{*}+(L-1)\left(J-\bar{I}^{*}\right) \mathbf{1}_{f\left(x_{t}\right) \geq s+J}\right] d t\right] \\
+E_{\mathcal{Q}}^{x_{0}}\left[\int_{0}^{T\left(x_{(\delta)}^{l}\right)} e^{-r t}(1-\tau)(L-1)\left(f_{(\delta)}\left(x_{t}\right)-s-I^{*}\right) \mathbf{1}_{s+I^{*}<f_{(\delta)}\left(x_{t}\right)<s+J} d t\right] .
\end{array}
$$

Using the same line of reasoning as in the previous section, the value of the levered firm satisfies for $f_{(\delta)}(x) \leq I^{*}+s$,

$$
\begin{aligned}
v_{(\delta)}^{\phi}\left(x_{0}, s\right)= & (1-\tau)\left(\frac{\delta x_{0}}{r-\mu}-\frac{c}{r}\right)-(1-\tau)\left(\frac{\delta x_{(\delta)}^{l}}{r-\mu}-\frac{c}{r}\right)\left(\frac{x_{0}}{x_{(\delta)}^{l}}\right)^{\vartheta} \\
& +\left[\frac{(1-\tau)(H-1) I^{*}}{r}+\frac{\tau s}{r}\right]\left[1-\left(\frac{x_{0}}{x_{(\delta)}^{l}}\right)^{\vartheta}\right]+A\left(x_{(\delta)}^{l}\right)\left(\frac{x_{0}}{x_{(\delta)}^{l}}\right)^{\vartheta} \\
& +\frac{(1-\tau)(L-1) \sigma\left[\left(c+s+I^{*}\right)^{1-\xi}-(c+s+J)^{1-\xi}\right]}{\lambda(\lambda-\sigma-b)(\lambda-b)\left(\delta x_{0}\right)^{-\xi}}\left[1-\left(\frac{x_{0}}{x_{(\delta)}^{l}}\right)^{\vartheta-\xi}\right],
\end{aligned}
$$

and for $s+I^{*} \leq f_{(\delta)}(x) \leq s+J$,

$$
\begin{aligned}
v_{(\delta)}^{\phi}\left(x_{0}, s\right)= & (1-\tau) L\left(\frac{\delta x_{0}}{r-\mu}-\frac{c+s}{r}\right)-(1-\tau)\left(\frac{\delta x_{(\delta)}^{l}}{r-\mu}-\frac{c+s}{r}\right)\left(\frac{x_{0}}{x_{(\delta)}^{l}}\right)^{\vartheta} \\
& +A\left(x_{(\delta)}^{l}\right)\left(\frac{x_{0}}{x_{(\delta)}^{l}}\right)^{\vartheta}+\frac{(1-\tau)(H-1) I^{*}+s}{r}\left[1-\left(\frac{x_{0}}{x_{(\delta)}^{l}}\right)^{\vartheta}\right] \\
& -(1-\tau)(L-1) \frac{I^{*}}{r}+\frac{(1-\tau)(L-1) \sigma\left(c+s+I^{*}\right)^{1-\vartheta}}{\lambda(\lambda+b)(\lambda+\sigma+b)\left(\delta x_{0}\right)^{-\vartheta}} \\
& +(1-\tau)(L-1) \frac{\left[\left(c+s+I^{*}\right)^{1-\xi}-(c+s+J)^{1-\xi}\right]}{\lambda(\lambda-\sigma-b)(\lambda-b)\left(\delta x_{0}\right)^{-\xi}}\left(\frac{x_{0}}{x_{(\delta)}^{l}}\right)^{\vartheta-\xi} \\
& +\frac{(1-\tau)(L-1) \sigma(c+s+J)^{1-\xi}}{\lambda(\lambda-\sigma-b)(\lambda-b)\left(\delta x_{0}\right)^{-\xi}}\left(\frac{x_{0}}{x_{(\delta)}^{l}}\right)^{\vartheta-\xi} \cdot
\end{aligned}
$$

\section{A.4 Value of the levered firm with financing constraints}

When the firm faces financing constraints, firm value satisfies Equation (19), the solution to which is given by (for $s+I^{*} \leq f_{(\delta)}(x) \leq s+J$ ) 


$$
\begin{aligned}
v_{(\delta)}^{\phi}\left(x_{0}, s\right)= & (1-\tau)(1+\pi)\left[\frac{\delta x_{0}}{r-\mu}-\frac{c}{r}-\left(\frac{\delta x_{(\delta)}^{l}}{r-\mu}-\frac{c}{r}\right)\left(\frac{x_{0}}{x_{(\delta)}^{l}}\right)^{\vartheta}\right] \\
& +A\left(x_{(\delta)}^{l}\right)\left(\frac{x_{0}}{x_{(\delta)}^{l}}\right)^{\vartheta}+\frac{(\tau-\pi) s}{r}\left[1-\left(\frac{x_{0}}{x_{(\delta)}^{l}}\right)^{\vartheta}\right] \\
& +(1-\tau)(H-1-\pi) \frac{\underline{I}^{*}}{r}\left[1-\left(\frac{x_{0}}{x_{(\delta)}^{l}}\right)^{\vartheta}\right] \\
& +(1-\tau) \frac{(h-1-\pi) \sigma\left(c+s+\underline{I}^{*}\right)^{1-\xi}}{\lambda(\lambda-\sigma-b)(\lambda-b)\left(\delta x_{0}\right)^{-\xi}}\left[1-\left(\frac{x_{0}}{x_{(\delta)}^{l}}\right)^{\vartheta-\xi}\right] \\
& +(1-\tau) \frac{(L-h) \sigma\left(c+s+\bar{I}^{*}\right)^{1-\xi}}{\lambda(\lambda-\sigma-b)(\lambda-b)\left(\delta x_{0}\right)^{-\xi}}\left[1-\left(\frac{x_{0}}{x_{(\delta)}^{l}}\right)^{\vartheta-\xi}\right] \\
& -\frac{(1-\tau)(L-1) \sigma(c+s+J)^{1-\xi}}{\lambda(\lambda-\sigma-b)(\lambda-b)\left(\delta x_{0}\right)^{-\xi}}\left[1-\left(\frac{x_{0}}{x_{(\delta)}^{l}}\right)^{\vartheta-\xi}\right] .
\end{aligned}
$$

\section{A.5 Firm value with future takeovers}

To compute firm value, we will need the following result.

Lemma 3. The Laplace transforms of the default and the takeover times are respectively given by

$$
\begin{aligned}
E_{\mathcal{Q}}^{x_{0}}\left[e^{-r T\left(x_{(\delta)}^{l}\right)} 1_{T\left(x_{(\delta)}^{l}\right)<T\left(x^{T}(s)\right)}\right] & =\frac{x_{0}^{\xi}-x_{0}^{\vartheta}\left(x^{T}(s)\right)^{\xi-\vartheta}}{\left(x_{(\delta)}^{l}\right)^{\xi}-\left(x_{(\delta)}^{l}\right)^{\vartheta}\left(x^{T}(s)\right)^{\xi-\vartheta}}, \\
E_{\mathcal{Q}}^{x_{0}}\left[e^{-r T\left(x^{T}(s)\right)} 1_{T\left(x^{T}(s)\right)<T\left(x_{(\delta)}^{l}\right)}\right] & =\frac{x_{0}^{\xi}-x_{0}^{\vartheta}\left(x_{(\delta)}^{l}\right)^{\xi-\vartheta}}{\left(x^{T}(s)\right)^{\xi}-\left(x^{T}(s)\right)^{\vartheta}\left(x_{(\delta)}^{l}\right)^{\xi-\vartheta}} .
\end{aligned}
$$

Proof. The proof of this result in a simple application of the Gisanov theorem to the Laplace transforms is presented in Revuz and Yor $(1999$, p. 72) for a standard Brownian motion.

Lemma 3 and similar calculations as above yield the value of the firm as $v_{(\delta)}^{\phi}\left(x_{0}, s\right)$

$$
\begin{aligned}
& =\frac{(1-\tau) \delta x_{0}}{r-\mu}-\frac{(1-\tau) \delta\left\{x^{T}(s)\left[x_{0}^{\xi}\left(x_{(\delta)}^{l}\right)^{\vartheta}-x_{0}^{\vartheta}\left(x_{(\delta)}^{l}\right)^{\xi}\right]+x_{(\delta)}^{l}\left[x_{0}^{\vartheta}\left(x^{T}(s)\right)^{\xi}-x_{0}^{\xi}\left(x^{T}(s)\right)^{\vartheta}\right]\right\}}{(r-\mu)\left[\left(x^{T}(s)\right)^{\xi}\left(x_{(\delta)}^{l}\right)^{\vartheta}-\left(x^{T}(s)\right)^{\vartheta}\left(x_{(\delta)}^{l}\right)^{\xi}\right]} \\
& +\frac{\tau s+(1-\tau)\left[(H-1) I^{*}-c\right]}{r}\left[1-\frac{x_{0}^{\xi}\left[\left(x^{T}(s)\right)^{\vartheta}-\left(x_{(\delta)}^{l}\right)^{\vartheta}\right]-x_{0}^{\vartheta}\left[\left(x^{T}(s)\right)^{\xi}-\left(x_{(\delta)}^{l}\right)^{\xi}\right]}{\left(x_{(\delta)}^{l}\right)^{\xi}\left(x^{T}(s)\right)^{\vartheta}-\left(x_{(\delta)}^{l}\right)^{\vartheta}\left(x^{T}(s)\right)^{\xi}}\right] \\
& +\frac{(1-\tau)(L-1) \sigma\left(c+s+I^{*}\right)\left(\delta x_{0}\right)^{\xi}}{\lambda(\lambda-b)(\lambda-\sigma-b)\left(c+s+I^{*}\right)^{\xi}}\left[1-\frac{x_{0}^{\xi}-x_{0}^{\vartheta}\left(x^{T}(s)\right)^{\xi-\vartheta}}{\left(x_{(\delta)}^{l}\right)^{\xi}-\left(x_{(\delta)}^{l}\right)^{\vartheta}\left(x^{T}(s)\right)^{\xi-\vartheta}}\left(\frac{x_{(\delta)}^{l}}{x_{0}}\right)^{\xi}\right] \\
& -(1-\tau)(L-1) \frac{x_{0}^{\xi}-x_{0}^{\vartheta}\left(x_{(\delta)}^{l}\right)^{\xi-\vartheta}}{\left(x^{T}(s)\right)^{\xi}-\left(x^{T}(s)\right)^{\vartheta}\left(x_{(\delta)}^{l}\right)^{\xi-\vartheta}}\left(\frac{\delta x^{T}(s)}{r-\mu}-\frac{c+s+I^{*}}{r}\right) \\
& -(1-\tau)(L-1) \frac{x_{0}^{\xi}-x_{0}^{\vartheta}\left(x_{(\delta)}^{l}\right)^{\xi-\vartheta}}{\left(x^{T}(s)\right)^{\xi}-\left(x^{T}(s)\right)^{\vartheta}\left(x_{(\delta)}^{l}\right)^{\xi-\vartheta}} \frac{\left(c+s+I^{*}\right) \sigma}{\lambda(\lambda+b)(\lambda+\sigma+b)}\left(\frac{\delta x^{T}(s)}{c+s+I^{*}}\right)^{\vartheta} \\
& +\frac{A\left(x_{(\delta)}^{l}\right)\left[x_{0}^{\xi}-x_{0}^{\vartheta}\left(x^{T}(s)\right)^{\xi-\vartheta}\right]}{\left(x_{(\delta)}^{l}\right)^{\xi}-\left(x_{(\delta)}^{l}\right)^{\vartheta}\left(x^{T}(s)\right)^{\xi-\vartheta}}+\frac{\left[v_{(1)}^{0}\left(x^{T}(s), s_{(1)}^{*}\right)-C\right]\left[x_{0}^{\xi}-x_{0}^{\vartheta}\left(x_{(\delta)}^{l}\right)^{\xi-\vartheta}\right]}{\left(x^{T}(s)\right)^{\xi}-\left(x^{T}(s)\right)^{\vartheta}\left(x_{(\delta)}^{l}\right)^{\xi-\vartheta}},
\end{aligned}
$$


with

$$
\begin{aligned}
v_{(1)}^{0}\left(x^{T}(s), s_{(1)}^{*}\right)= & (1-\tau)\left(\frac{x^{T}(s)}{r-\mu}+\frac{(H-1) I^{*}-c}{r}\right)+\frac{\tau s_{(1)}^{*}}{r}\left(1-\left(\frac{x^{T}(s)}{x_{(1)}^{l}}\right)^{\vartheta}\right) \\
& -(1-\tau)\left(\frac{x_{(1)}^{l}}{r-\mu}-\frac{c-(H-1) I^{*}}{r}\right)\left(\frac{x^{T}(s)}{x_{(1)}^{l}}\right)^{\vartheta}+A\left(x_{(1)}^{l}\right)\left(\frac{x^{T}(s)}{x_{(1)}^{l}}\right)^{\vartheta}
\end{aligned}
$$

The expression reported in Equation (47) for firm value is similar to that derived above. The first two terms on the right-hand side account for the expected present value of operating inflows until the control change. The third term is the sum of the debt tax shield, operating costs, and positive-NPV projects until the change of control. The fourth, fifth, and sixth terms account for the overinvestment cost. Finally, the seventh and eighth terms reflect firm value following either default or the control transaction.

\section{References}

Andrade, G., and S. Kaplan, 1998, "How Costly is Financial (not Economic) Distress? Evidence from Highly Leveraged Transactions that Became Distressed," Journal of Finance, 53, 1443-1493.

Barclay, M., E. Morellec, and C. Smith, 2002, "On the Debt Capacity of Growth Options," working paper, University of Rochester.

Berger, P., E. Ofek, and D. Yermak, 1997, "Managerial Entrenchment and Capital Structure Decisions," Journal of Finance, 52, 1411-1438.

Blanchard, O., F. Lopez-de-Silanes, and A. Shleifer, 1994, "What do Firms do with Cash Windfalls?," Journal of Financial Economics, 36, 337-360.

Brady, B., and R. Bos, 2002, Record Defaults in 2001: The Result of Poor Credit Quality and a Weak Economy, Standard \& Poor's.

David, A., 2001, "Pricing the Strategic Value of Putable Securities in Liquidity Crises," Journal of Financial Economics, 59, 63-99.

Duffie, D., and D. Lando, 2001, "Term Structures of Credit Spreads with Incomplete Accounting Information," Econometrica, 69, 633-664.

Dumas, B., 1991, "Super Contact and Related Optimality Conditions," Journal of Economic Dynamics and Control, 15, 675-685.

Fan, H., and S. Sundaresan, 2000, "Debt Valuation, Renegotiation, and Optimal Dividend Policy," Review of Financial Studies, 13, 1057-1099.

Fazzari, S., R. Hubbard, and B. Petersen, 1988, "Financing Constraints and Corporate Investment," Brookings Papers on Economic Activity, 88, 141-195.

François, P., and E. Morellec, 2004, "Capital Structure and Asset Prices: Some Effects of Bankruptcy Procedures," forthcoming in Journal of Business, 77.

Froot, K., D. Scharfstein, and J. Stein, 1993, "Risk Management: Coordinating Corporate Investment and Financing Policies," Journal of Finance, 48, 1629-1658.

Garvey, G., and G. Hanka, 1999, "Capital Structure and Corporate Control: The Effect of Antitakeover Statutes on Firm Leverage," Journal of Finance, 54, 547-580.

Goldstein, R., N. Ju, and H. Leland, 2001, "An Ebit-Based Model of Dynamic Capital Structure," Journal of Business, 74, 483-512.

Graham, J., 2000, "How Big are the Tax Benefits of Debt?," Journal of Finance, 55, 1901-1941. 
Hamilton, D., G. Gupton, and A. Berthault, 2001, Default and Recovery Rates of Bond Issuers: 2000, Moody's Investor Service.

Harford, J., 1999, “Corporate Cash Reserves and Acquisitions,” Journal of Finance, 54, 1969-1997.

Hennessy, C., 2003, "Tobin's Q, Debt Overhang, and Investment," working paper, University of California-Berkeley.

Holmstrom, B., and P. Milgrom, 1987, "Aggregation and the Linearity in the Provision of Intertemporal Incentives," Econometrica, 55, 303-328.

Jensen, M., 1986, "Agency Costs of Free Cash Flow, Corporate Finance and Takeovers," American Economic Review, 76, 323-329.

Jensen, M., and W. Meckling, 1976, “Theory of the Firm: Managerial Behavior, Agency Costs and Ownership Structure," Journal of Financial Economics, 3, 305-360.

Johnson, S., 2002, "Debt Maturity and the Effects of Growth Opportunities and Liquidity Risk on Leverage," Review of Financial Studies, 16, 209-236.

Ju, N., R. Parrino, A. Poteshman, and M. Weisbach, 2003, "Horses and Rabbits? Optimal Dynamic Capital Structure from Shareholder and Manager Perspectives," working paper, University of Maryland.

Jung, K., Y. Kim, and R. Stulz, 1996, "Timing, Investment Opportunities, Managerial Discretion, and the Security Issue Decision,” Journal of Financial Economics, 42, 159-185.

Karatzas, I., and S. Shreve, 1991, Brownian Motion and Stochastic Calculus (2nd ed.), Springer Verlag, Berlin.

Keenan, S. C., I. Shotgrin, and J. Sobehart, 1999, Historical Default Rates of Corporate Bond Issuers, 1920-1998, Moody's Investor Service.

Lambrecht, B., 2001, "The Impact of Debt Financing on Entry and Exit in a Duopoly," Review of Financial Studies, 14, 765-804.

Leland, H., 1994, “Corporate Debt Value, Bond Covenants, and Optimal Capital Structure," Journal of Finance, 49, 1213-1252.

Leland H., 1998, “Agency Costs, Risk Management, and Capital Structure,” Journal of Finance, 53, $1213-1243$.

Leland, H., and K. Toft, 1996, "Optimal Capital Structure, Endogenous Bankruptcy and the Term Structure of Credit Spreads,” Journal of Finance, 51, 987-1019.

Mello, A., and J. Parsons, 1992, "Measuring the Agency Cost of Debt," Journal of Finance, 47, 1887-1904.

Modigliani, F., and M. Miller, 1958, "The Cost of Capital, Corporation Finance, and the Theory of Investment," American Economic Review, 48, 261-297.

Morellec, E., 2001, “Asset Liquidity, Capital Structure and Secured Debt," Journal of Financial Economics, 61, 173-206.

Morellec, E., and C. Smith, 2002, "Investment Policy, Financial Policies, and the Control of Agency Conflicts," working paper, University of Rochester.

Myers, S., 1977, "Determinants of Corporate Borrowing,” Journal of Financial Economics, 5, 147-175.

Parrino, R., A. Poteshman, and M. Weisbach, 2001, "Measuring Investment Distortions When Risk-Averse Managers Decide Whether to Undertake Risky Projects,” working paper, University of Texas.

Parrino, R., and M. Weisbach, 1999, "Measuring Investment Distortions Arising from Stockholder-Bondholder Conflicts," Journal of Financial Economics, 53, 3-42. 
Rajan, R., and L. Zingales, 1995, "What Do We Know About Capital Structure? Some Evidence from International Data," Journal of Finance, 50, 1421-1467.

Revuz, D., and M. Yor, 1999, Continuous Martingales and Brownian Motion (3rd ed.), Springer Verlag, Berlin.

Shättler, H., and J. Sung, 1993, "The First-Order Approach to Continuous-Time Principal-Agent Problems with Exponential Utility," Journal of Economic Theory, 61, 331-371.

Smith, C., and R. Watts, 1992, "The Investment Opportunity Set, and Corporate Financing, Dividend, and Compensation Policies," Journal of Financial Economics, 32, 262-292.

Stulz, R., 1990, "Managerial Discretion and Optimal Financial Policies," Journal of Financial Economics, 26, 3-27.

Titman, S., and S. Tsyplakov, 2002, “A Dynamic Model of Optimal Capital Structure," working paper, University of Texas.

Zwiebel, J., 1996, "Dynamic Capital Structure Under Managerial Entrenchment," American Economic Review, 86, 1197-1215. 